\title{
NUMERICAL INVESTIGATIONS ON THE EFFECTS OF $T$ - STRESS IN MODE I CREEP CRACK
}

\author{
Yanwei Dai \\ Department of Engineering Mechanics, AML, Tsinghua University, \\ Beijing 100084, China \\ National Engineering Research Centre for Advanced Polymer Processing Technology, Zhengzhou University, \\ Zhengzhou 450002, China \\ daiyw13@mails.tsinghua.edu.cn \\ Yinghua $\mathrm{Liu}^{1}$ \\ Department of Engineering Mechanics, AML, Tsinghua University, \\ Beijing 100084, China \\ yhliu@mail.tsinghua.edu.cn \\ Haofeng Chen \\ Department of Mechanical \& Aerospace Engineering, University of Strathclyde \\ James Weir Building, 75 Montrose Street, Glasgow, G1 1XJ, UK \\ haofeng.chen@strath.ac.uk
}

Abstract: The effects of $T$-stress on the stress field, creep zone and constraint effect of the mode I crack tip in power-law creeping solids are presented based on finite element (FE) analysis in the paper. The characteristics of the crack tip field in power-law creep solids by considering low negative $T$-stress and high positive $T$-stress are studied in the paper. The differences of $T$-stress effect on the crack tip field between power-law creeping solids and elastoplastic materials are also clarified. A modified parameter is proposed to characterize the influence of $T$-stress on creep zone. The constraint parameter $Q$ under both small scale creep and large scale creep with various $T$-stresses for the modified boundary layer (MBL) model and various specimens with different crack depths are given. The applicability and the limitation of the MBL model for creep crack are also investigated. The inherent connection between $T$-stress and $Q$-parameter is discussed. The investigations given in this paper can further promote the understanding of $T$-stress effect and constraint effect on the mode I creep crack.

Keywords: T-stress; Power-law creep; Constraint effect; Creep zone; Finite element method

\footnotetext{
${ }^{1}$ Corresponding author: yhliu@mail.tsinghua.edu.cn (Y.H. Liu)
} 


\section{Introduction}

The accurate description of crack tip field is crucial to propose a fracture criterion and make a more precise prediction on crack growth. With the increasing demands on the reduction of gas emission and energy saving in this century, a more accurate evaluation of crack contained structures under high temperature is required. As the single fracture parameter determined HRR (Hutchinson, 1968; Rice and Rosengren, 1968) term or RR term (Riedel and Rice, 1980) can not represent the full field of mode I creep crack sufficiently, several parameters have been proposed to characterize the socalled "constraint effect", e.g. $Q$ (Shih et al., 1993), $A_{2}^{*}$ (Chao et al., 2001), $Q_{2}$ (Nguyen et al., 2000), $R$ (Wang et al., 2010), $R^{*}$ (Tan et al., 2014) and $A_{\mathrm{c}}$ (Ma et al., 2015). According to Budden and Ainsworth (1997), the constraint effect on crack in creeping solids is found to be important as it can affect the safe boundary of timedependent failure assessment diagram to some extent. Due to the significant implications of constraint effect on the failure assessment for crack contained structures at elevated temperature, the creep crack considering high order term solutions were also recently explored by many researchers from different aspects (Dai et al., 2017; Matvienko et al., 2013; Nikbin, 2004; Shlyannikov et al., 2011; Yatomi et al., 2006).

The $T$-stress was the first non-singular term of William's expansion (Williams, 1957) for linear elastic crack tip field. The influence of $T$-stress on the plastic region size of the modified boundary layer (MBL) model and different specimens was presented by Larsson and Carlsson (1973). The effect of $T$-stress on the crack tip of nonlinear plastic materials was revealed by Du and Hancock (1991). Although the role of $T$-stress in elastoplastic material was verified to be important on the constraint effect parameter $Q$ and plastic zone size (Du and Hancock, 1991; Larsson and Carlsson, 1973; Shih et al., 1993), no available literatures have been found to discuss the relationship of $Q$ and $T$-stress for creep crack tip stress field, and the applicability of $T$-stress in creeping solids is not revealed yet.

The importance and effect of $T$-stress on fracture behaviours of nonlinear 
hardening materials and linear elastic materials have been clarified in many aspects, e.g. the influence of $T$-stress on crack growth resistance for ductile material (Tvergaard and Hutchinson, 1994), crack path of composites (Becker Jr et al., 2001; Tvergaard, 2008), crack closure effect (Roychowdhury and Dodds Jr, 2004) and mixed mode fracture (Liu and Chao, 2003). There are also many other discussions on $T$-stress which can be referred as follows (Ayatollahi et al., 2002; Ayatollahi and Hashemi, 2007; Ayatollahi and Sedighiani, 2012; Broberg, 1999; Chen, 2000; Fett, 1998; Gao and Chiu, 1992; Henry and Luxmoore, 1994; Ye et al., 1992). It should be noted that most of the discussions on $T$-stress are for elastic and plastic material. However, the influence of $T$ stress on the crack tip field in creeping solids has not been investigated thoroughly.

The MBL formulation under small scale yielding is a powerful tool to study the constraint effect as well as the role of $T$-stress on the crack tip field, and many problems were solved by this method e.g. three dimensional crack front field descriptions of a thin plate (Nakamura and Parks, 1990), characterization of constraint effect for crack tip field in elastic-plastic material (Yuan and Brocks, 1998), influence of residual stress on constraint effect (Ren et al., 2009) and so on. As a matter of fact, the MBL formulation was extended to creep regime by Matvienko et al. (2013), and they presented the variation of constraint parameter $A_{2}^{*}$ with different $T$-stress levels for three dimensional crack front. The mismatched MBL for creeping solids was adopted by Dai et al. (2016) to study the constraint effect caused by material mismatch. It should be noted that the quantified investigations about the influence of $T$-stress on the creep crack field as well as the constraint effect for creep crack is still unknown in the available references.

The overall aim of this paper is to study the influence of $T$-stress on the twodimensional creep crack tip fields under plane strain condition with finite element (FE) method. The structure of this paper is organized as follows. The theoretical background is given in Section 2. In Section 3, the constitutive equations, the geometry sizes, the loading conditions and the FE models are figured out. The numerical procedures and material properties are also illustrated in Section 3. The results and discussions are 
presented in Section 4. The conclusions are drawn in the last section.

\section{Theoretical background}

\subsection{Non-singular term, i.e. T-stress}

The full expansions of the crack tip stress field for linear elastic solid was presented by Williams (1957) as below:

$$
\sigma_{i j}(r, \theta)=C_{1} r^{-1 / 2} f_{i j}(\theta)+C_{2} r^{0} g_{i j}(\theta)+C_{3} r^{1 / 2} h_{i j}(\theta)+\cdots
$$

where $r$ is the distance from crack tip, $C_{1}, C_{2}$ and $C_{3}$ are the constants related with loading, and $f_{i j}(\theta), g_{i j}(\theta), h_{i j}(\theta)$ are dimensionless functions of different orders. By considering the first order non-singular term of Williams expansions, the crack tip stress field can be written as (Du and Hancock, 1991)

$$
\sigma_{i j}(r, \theta)=\frac{K_{\mathrm{I}}}{\sqrt{2 \pi r}} f_{i j}(\theta)+T \delta_{1 i} \delta_{1 j}
$$

where $K_{\mathrm{I}}$ is the stress intensity factor (SIF) for the mode I crack, $T$ is the $T$-stress and $\delta_{i j}$ is the Kronecker delta. The relationship between $K_{\mathrm{I}}$ and $T$-stress can be written as (Sherry et al., 1995)

$$
T=\frac{C_{\mathrm{B}} K_{\mathrm{I}}}{\sqrt{\pi a}}
$$

where $a$ is the crack length. $C_{\mathrm{B}}$ in Eq. (3) is a dimensionless parameter which depends on geometrical shape and loading mode of the cracked structure, and also named as the stress biaxiality factor.

\subsection{Q-parameter in power-law creeping solids}

The famous power-law constitutive equation can be presented as (Norton, 1929)

$$
\dot{\varepsilon}=\dot{\varepsilon}^{\mathrm{e}}+\dot{\varepsilon}^{\mathrm{c}}=\frac{\dot{\sigma}}{E}+\dot{\varepsilon}_{0}\left(\frac{\sigma}{\sigma_{0}}\right)^{n}
$$


where $\dot{\varepsilon}^{\mathrm{e}}, \dot{\varepsilon}^{\mathrm{c}}, \dot{\varepsilon}_{0}, \dot{\sigma}$ and $\sigma_{0}$ is the elastic strain rate, the creep strain rate, the reference strain rate, the stress rate and the reference stress, respectively. As usual, Eq. (4) can be simplified as $\dot{\varepsilon}^{\text {c }}=A \sigma^{n}$, and the creep coefficient $A$ is identical to $\dot{\varepsilon}_{0} / \sigma_{0}^{n}$. Herein, $n$ is the creep exponent.

The stress field for a crack in power-law creeping solids is presented as below (Riedel and Rice, 1980):

$$
\sigma_{i j}(r, \theta)=\sigma_{0}\left(\frac{C(t)}{\sigma_{0} \dot{\varepsilon}_{0} I_{n} r}\right)^{1 /(n+1)} \tilde{\sigma}_{i j}(\theta)
$$

where $C(t), I_{n}, \sigma_{0}, \dot{\varepsilon}_{0}$ are the $C(t)$-integral, the integral constant, the reference stress and the reference creep strain rate, respectively. Note that $I_{n}$ relies on the crack front stress state. $C(t)$-integral is replaced by $C^{*}$-integral under extensive creep when it presents to be path-independent. According to the Hoff's analogy (Hoff, 1954), the $C(t)-Q$ two parameter theory of a power-law creep crack is presented as (Budden and Ainsworth, 1997; Shih et al., 1993):

$$
\sigma_{i j}(r, \theta)=\sigma_{0}\left(\frac{C(t)}{\sigma_{0} \dot{\varepsilon}_{0} I_{n} r}\right)^{1 /(n+1)} \tilde{\sigma}_{i j}(n, \theta)+Q \sigma_{0} \delta_{i j}
$$

in which the quantities in the above equation have the same meaning as those defined in Eq. (5), and $Q$ is the $Q$-parameter which can be computed by the following form:

$$
Q=\frac{\sigma_{22}-\sigma_{22}^{\mathrm{HRR}}}{\sigma_{0}} \quad \text { at } \theta=0^{\circ}
$$

where $\sigma_{22}^{\mathrm{HRR}}$ is the opening stress of the HRR field. Except Eq. (7), there also exists the following expression to characterize the constraint effect for strain hardening material under small scale yielding condition which is expressed as (O'Dowd and Shih, 1994)

$$
Q=\frac{\sigma_{22}-\sigma_{22}^{\mathrm{SSY}, T=0}}{\sigma_{0}} \text { at } \theta=0^{\circ}, \bar{r}=2 \sigma_{0} / J
$$

where $\sigma_{22}^{\text {sSY,T=0}}$ is the opening stress of HRR field under small scale yielding with $T=0$ 
and $\bar{r}$ is the normalized distance which is always adopted in the characterization of crack tip for elastoplastic materials. Herein, Eq. (8) is introduced into small scale creep regime directly and proposed as:

$$
Q=\frac{\sigma_{22}-\sigma_{22}^{\mathrm{sSC}, T=0}}{\sigma_{0}} \text { at } \theta=0^{\circ}
$$

in which $\sigma_{22}^{\mathrm{SSC}, T=0}$ is the opening stress under small scale creep with $T=0$. To distinguish the transient creep and steady state creep, the transition time is defined as (Riedel and Rice, 1980)

$$
t_{\mathrm{T}}=\frac{\left(1-v^{2}\right) K_{\mathrm{I}}^{2}}{(n+1) E C^{*}}
$$

where the quantities in Eq. (10) are the same as those defined previously, i.e. $K_{\mathrm{I}}, v$, $n$ and $C^{*}$ are SIF, Poisson's ratio, creep exponent and $C^{*}$-integral, respectively.

For a creep crack tip field, a normalized distance can be adopted as below (Bettinson et al., 2001):

$$
\bar{r}=r /\left(C^{*} / \sigma_{0} \dot{\varepsilon}_{0}\right)
$$

in which $r, C^{*}, \sigma_{0}$ and $\dot{\varepsilon}_{0}$ are the radial distance away from crack tip, $C^{*}$-integral, reference stress and reference strain rate, respectively. Herein, it should also be pointed out that the actual distance is also used widely to describe the variation of $Q$-parameter in radial direction for creep crack according to these investigations listed as follows (Tan et al., 2014; Wang et al., 2010; Zhao et al., 2015a).

\section{Finite element model}

The power-law creep constitutive equation is adopted to perform the FE calculations and the material properties used in the analysis can be found in Table 1 (Zhao et al., 2015b). To perform the analysis, three typical specimens are adopted here, i.e. central cracked plate (CCP), single edge cracked plate (SECP) and compact tension (CT) cracked plate. The specific geometries for these cases are shown in Fig. 1. The 
widths for CCP, SECP and CT are fixed as $40 \mathrm{~mm}$. The height for CCP, SECP and CT are $80 \mathrm{~mm}, 80 \mathrm{~mm}$ and $48 \mathrm{~mm}$, respectively. There are totally six cases considered here, i.e. CCP, SECP and CT with both shallow crack and deep crack, and the detailed geometry sizes can be found in Table 2 .

Except the specimens, the configuration of the MBL model is also presented in Fig. 1. The applied boundary condition of the MBL model under two dimensional plane strain condition is adopted as:

$$
\left\{\begin{array}{l}
u_{x}=\frac{K_{\mathrm{I}}}{E} \sqrt{\frac{r}{2 \pi}}(1+v)(3-4 v-\cos \theta) \cos \frac{\theta}{2}+\frac{T}{E} r\left(1-v^{2}\right) \cos \theta \\
u_{y}=\frac{K_{\mathrm{I}}}{E} \sqrt{\frac{r}{2 \pi}}(1+v)(3-4 v-\cos \theta) \sin \frac{\theta}{2}-\frac{T}{E} v(1+v) r \sin \theta
\end{array}\right.
$$

where $v, r, E, \theta$ and $T$ are Poisson's ratio, radial distance from crack tip, Young's modulus, polar angle of the local coordinates (shown in Fig. 1(d)) and the applied $T$-stress at the outer boundary, respectively. Herein, $K_{\mathrm{I}}$ in Eq. (12) can be calculated as:

$$
K_{\mathrm{I}}=\sqrt{E J /\left(1-v^{2}\right)}
$$

where $J$ is the $J$-integral applied at the outer boundary. The radius of the MBL model is $1000 \mathrm{~mm}$. For the convenience of calculation, a half model with symmetric boundary is adopted during the computation. The polar coordinate system for the creep crack tip is shown in Fig. 1.

\begin{tabular}{cc} 
Table 1 Material properties used in the calculations \\
\hline Material property & \\
\hline Young's modulus, $E$ & $125 \mathrm{GPa}$ \\
Poisson's ratio, $v$ & 0.3 \\
Yielding stress, $\sigma_{0}$ & $180 \mathrm{MPa}$ \\
Creep exponent, $n$ & 5.23 \\
Creep coefficient, $A$ & $2.64 \mathrm{E}-16 \mathrm{MPa}^{-n}$ \\
\hline
\end{tabular}

The FE code ABAQUS is adopted here to perform the numerical computations. For all the calculated cases, the element type is CPE8R and the crack type is focused 
sharp crack with collapsed element side which can guarantee the HRR singularity. The element number of CCP1, CCP2, SECP1, SECP2, CT1 and CT2 listed in Table 2 are 5736, 5848, 3844, 3844, 10528 and 7097, respectively. The specific FE grids for CT, CCP and SECP can be seen in Fig. 1. The FE grids of crack tips for these analysed specimens are kept to be the same. The element type for the MBL model is the same as the specimens, and the minimum size of the element is $0.01 \mathrm{~mm}$. The total element number for the MBL model is 1792, and the detailed FE grids can be seen in Fig. 1. The applied loads $P$ for various specimens shown in Fig. 1 has been presented in the fourth row of Table 2.

Table 2 Specimens, loads and related SIFs used in the computations

\begin{tabular}{cccccc}
\hline Specimen & $a / W$ & $\begin{array}{c}\text { SIF by ABAQUS } \\
\left(\mathrm{MPa} \bullet \mathrm{mm}^{1 / 2}\right)\end{array}$ & Applied loads & $\begin{array}{c}\text { Theoretical SIF } \\
\left(\mathrm{MPa} \bullet \mathrm{mm}^{1 / 2}\right)\end{array}$ & $\begin{array}{c}\text { Relative } \\
\text { error }\end{array}$ \\
\hline CT1 & 0.15 & 142.1 & $P=250.3 \mathrm{~N}$ & $144.32^{*}$ & $1.50 \%$ \\
CT2 & 0.5 & 142.1 & $P=103.4 \mathrm{~N}$ & $146.49^{*}$ & $3.00 \%$ \\
CCP1 & 0.15 & 142.1 & $P=45.65 \mathrm{MPa}$ & $142.65^{-}$ & $1.16 \%$ \\
CCP2 & 0.5 & 142.1 & $P=21.35 \mathrm{MPa}$ & $141.52^{-}$ & $0.297 \%$ \\
SECP1 & 0.125 & 142.1 & $P=29.50 \mathrm{MPa}$ & $143.56^{+}$ & $1.02 \%$ \\
SECP2 & 0.5 & 142.1 & $P=6.35 \mathrm{MPa}$ & $142.53^{+}$ & $0.302 \%$ \\
\hline
\end{tabular}

The FE meshes given in this paper are validated to be accurate enough as the linear elastic stress intensity factors (SIFs) for all the calculated models are found to be unchanged with the increase of the element number. To verify this point, the SIFs of all the calculated cases are shown in Table 2 . All the SIFs of the analysed cases are nearly kept to be the same, i.e. $K_{\mathrm{I}}=142.1 \mathrm{MPa} \cdot \mathrm{mm}^{1 / 2}$, under different loading conditions (see Table 2). It can be found that the SIFs calculated with the adopted FE meshes coincide with the empirical solutions given by Tada et al. (2000) (see symbol “*” in Table 2), Brown (1966) (see symbol “-” in Table 2) and Fett (2009) (see symbol “+” in Table 2) very well as the relative errors among these calculations are less than 3\%, which indicates that the SIF calculated by contour integral method is accurate and robust enough, and the FE meshes are refined. The $C(t)$-integral given in the paper is also obtained with contour integral method and the $C(t)$-integral is extracted from the ABAQUS with average of ten contours ahead of crack tip. The $C^{*}$-integral is obtained 
when the $C(t)$-integral presents to be path-independent.
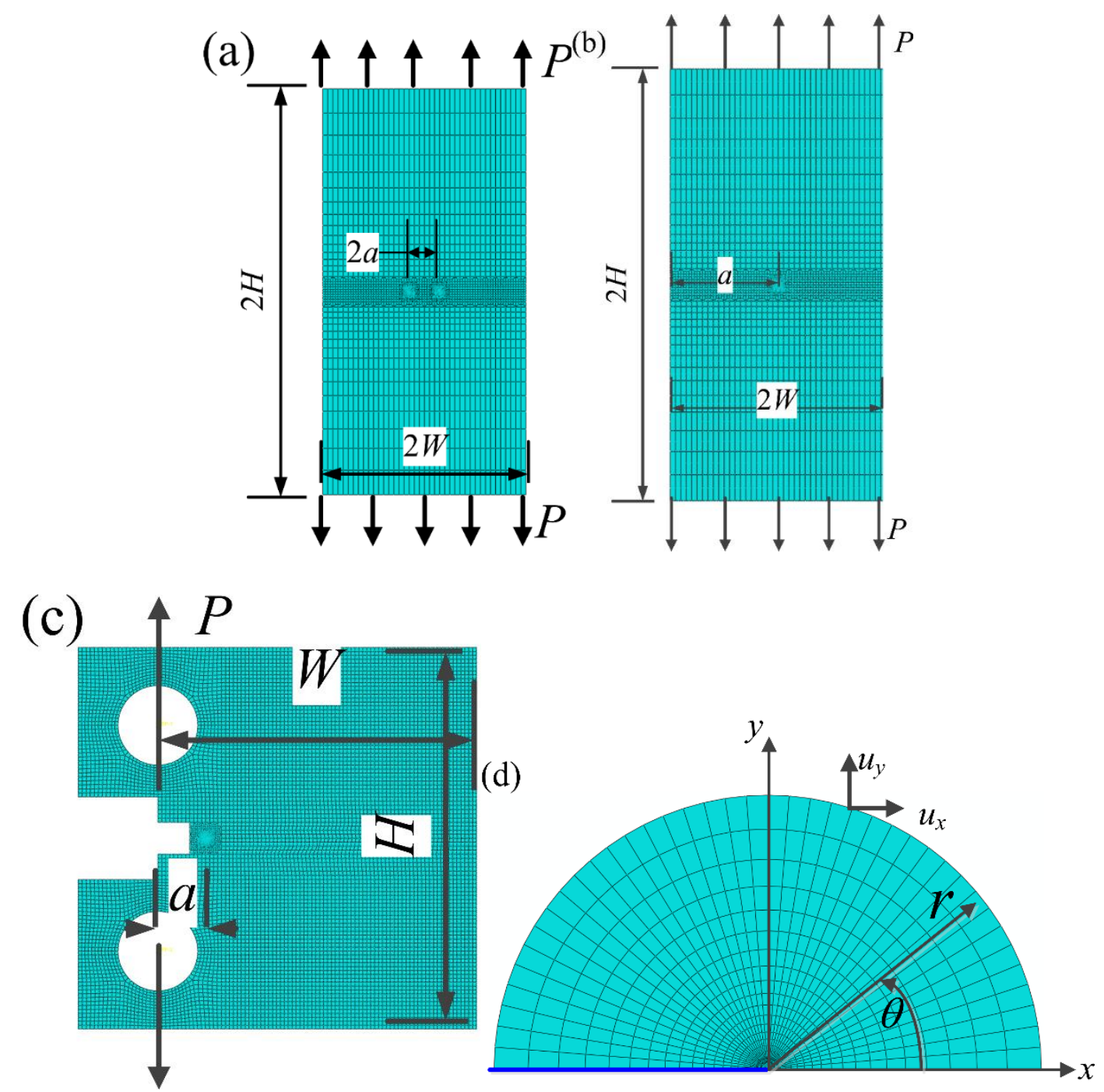

Fig. 1 Configurations and FE meshes for (a) CCP specimen, (b) SECP specimen, (c) CT specimen and (d) MBL model

To simulate the finite strain deformation, the FE meshes presented in Fig. 2 are used to perform the analysis. The CPE4H element type is adopted with finite strain deformation mode triggered. The specific FE meshes for the CCP specimen and the MBL model can be seen in Fig. 2. For the CCP specimen, a quarter model shown in Fig. 2 is adopted to perform the analysis of the creep crack tip field under finite strain deformation mode. Meanwhile, the FE grids of the crack tip for the MBL model under finite strain deformation are similar to that of CCP specimen (shown in Fig. 2 (c)), which are with a total element number of 2060. 


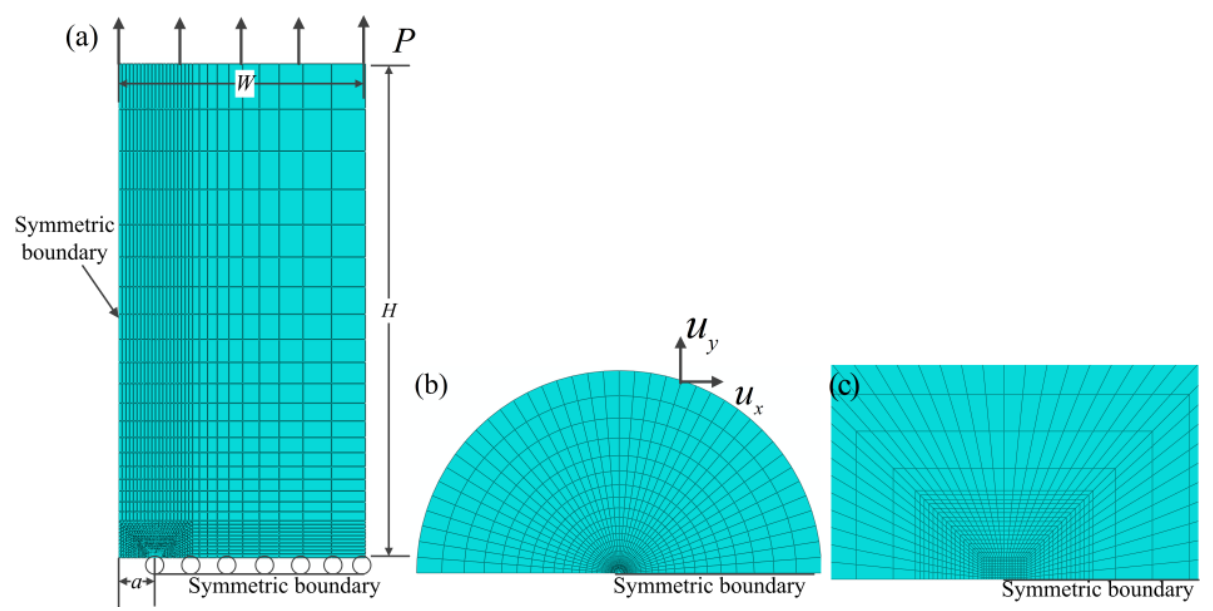

Fig. 2 FE meshes under finite strain deformation mode for (a) CCP specimen, (b) MBL model and (c) crack tip

\section{Results and discussions}

\subsection{Determination of T-stress for creep crack}

Many methods have been developed to calculate the $T$-stress of crack tip fields in linear elastic materials and nonlinear strain hardening materials, e.g. FE method, finite difference method and so on (Ayatollahi et al., 1998; Chen, 2000; Meshii et al., 2010; Yang and Ravi-Chandar, 1999). The stress field for mode I crack by considering the $T$ stress is written as (expansion of Eq.(2)):

$$
\left\{\begin{array}{l}
\sigma_{11}(r, \theta)=\frac{K_{\mathrm{I}}}{\sqrt{2 \pi r}} \cos \frac{\theta}{2}\left(1-\sin \frac{\theta}{2} \sin \frac{3 \theta}{2}\right)+T \\
\sigma_{12}(r, \theta)=\frac{K_{\mathrm{I}}}{\sqrt{2 \pi r}} \sin \frac{\theta}{2} \cos \frac{\theta}{2} \cos \frac{3 \theta}{2} \\
\sigma_{22}(r, \theta)=\frac{K_{\mathrm{I}}}{\sqrt{2 \pi r}} \cos \frac{\theta}{2}\left(1+\sin \frac{\theta}{2} \sin \frac{3 \theta}{2}\right)
\end{array}\right.
$$

in which $r, \theta$ are the radial distance away from crack tip and polar angle in the polar coordinate (see Fig. 1 (d)), respectively. $\sigma_{11}, \sigma_{22}$ and $\sigma_{12}$ are the radial stress, the tangential stress (or the opening stress) and the shearing stress, respectively. With Eq.(14), the $T$-stress can be obtained with the following form:

$$
T=\sigma_{11}-\sigma_{22} \quad \text { for } \theta=0
$$


where $\sigma_{11}$ and $\sigma_{22}$ are the radial stress and the tangential stress obtained ahead of crack, respectively. To validate Eq.(15), the solutions of $\sigma_{11}-\sigma_{22}$ along $\theta=0^{\circ}$ under the MBL model are presented in Fig. 3. It can be seen that the value of $\sigma_{11}-\sigma_{22}$ is identical to the $T$-stress that applied at the outer boundary closely at the creep time $t_{\mathrm{T}}$. However, it should be noted that the $T$-stress is not identical to the applied $T$-stress at the outer boundary in the region where $r$ is less than $10 \mathrm{~mm}$ as the region is dominated by creep regime. The length of the creep boundary ahead of crack is about $1 \%$ of the entire length of the radius of the MBL, which indicates that the creep regime is still under transient creep (small scale creep). With the increase of the creep time, the $\sigma_{11}-\sigma_{22}$ near the crack tip will deviate significantly from the $T$-stress applied at the outer boundary. This reveals that the MBL model is applicable under the transient creep and will not be applicable under extensive creep as the $T$-stress defined in the linear elastic field does not exist when the whole model is entirely dominated by creep strain.

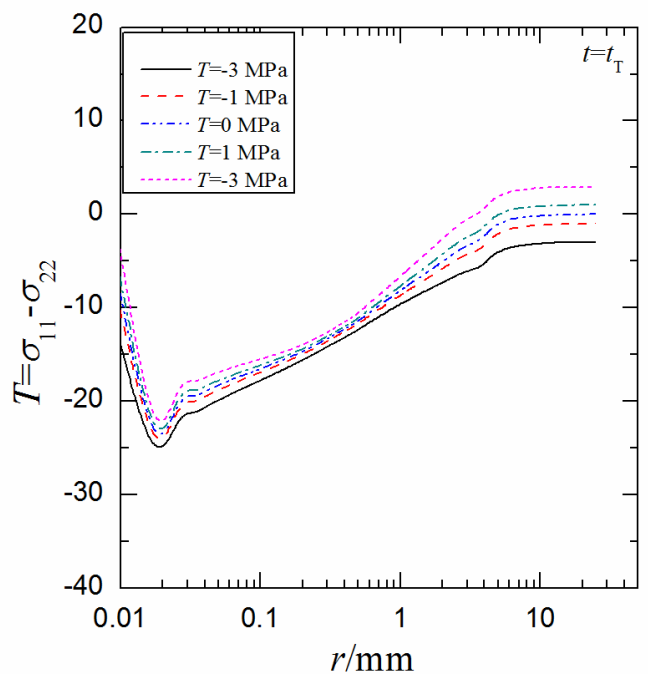

Fig. 3 Variations of $\sigma_{11}-\sigma_{22}$ along $\theta=0^{\circ}$ in radial direction at the transition time

\subsection{Influence of $T$-stress on $C(t)$-integral and equivalent creep zone}

\subsubsection{C(t)-integral}

The relationship between $C(t)$-integral and SIF, $K_{\mathrm{I}}$, at transient creep range can be 
presented as Eq. (10). The $C(\mathrm{t})$-integrals of different specimens under transient creep and extensive creep are presented in Fig. 4. Herein, the average of the $C(t)$-integrals from ten contours ahead of crack tip is adopted as the computed $C(t)$-integral for each specimen. It can be seen that the $C(t)$-integrals present to be very close with each other except those of the two CT specimens under transient creep regime. For all these cracked specimens, $C(t)$-integral should be the same theoretically in a short creep time according to Eq. (10) as the $K_{\mathrm{I}}$ of these specimens are the same which has been presented in Table 2. From Fig. 4, it can be seen that $C(t)$-integrals of CCP1, CCP2, SECP1 and SECP2 present the same tendency, however, $C(t)$-integrals for CT1 and CT2 are much higher than those of other five specimens. Note that they have nearly the same SIF which implies that the CT specimen is sensitive to the initiative value of SIF. When the $C(t)$-integral approaches to the extensive creep, $C(t)$-integral becomes the $C^{*}$ integral. The $C^{*}$-integral under different specimens are given in Table 3. From the results of the transition time given in Table 3 , it can be found that the transition time $t_{\mathrm{T}}$ for the MBL model is much larger than those of the other specimens, which implies that the time to reach the extensive creep for the MBL model is much longer.

Table $3 C^{*}$-integral and transition time of different specimens

\begin{tabular}{ccc}
\hline Specimen & $C^{*}($ MPa $\bullet \mathrm{mm} /$ hour $)$ & Transition time (hour) \\
\hline CT1 & $7.13 \mathrm{E}-06$ & 3638.58 \\
CT2 & $3.33 \mathrm{E}-05$ & 779.46 \\
CCP1 & $7.37 \mathrm{E}-05$ & 351.75 \\
CCP2 & $1.55 \mathrm{E}-05$ & 1668.43 \\
SECP1 & $1.18 \mathrm{E}-05$ & 2188.15 \\
SECP2 & $8.75 \mathrm{E}-07$ & 29639.14 \\
MBL & $2.14 \mathrm{E}-07$ & 121131.81 \\
\hline
\end{tabular}



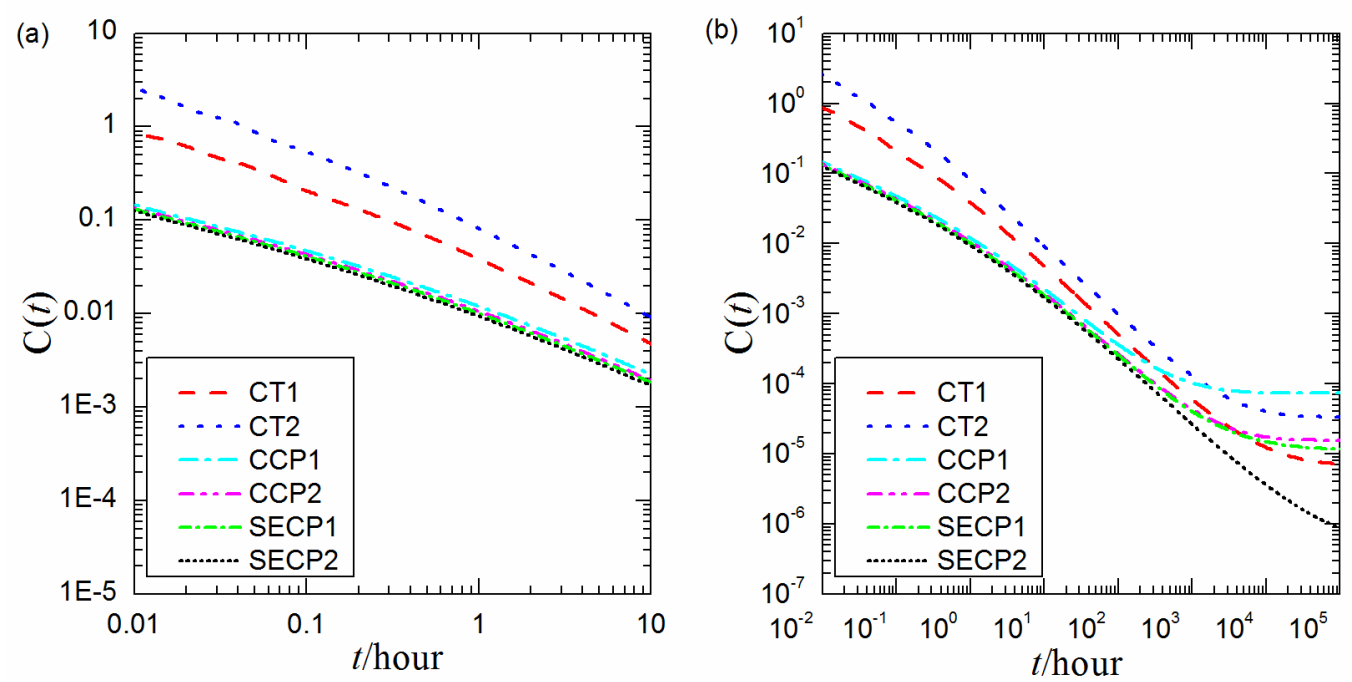

Fig. 4 Variations of $C(t)$-integral under (a) transient creep and (b) extensive creep

\subsubsection{Equivalent creep zone for the MBL model}

The creep zone, which was given by Riedel and Rice (1980), can be presented as

$$
r_{\mathrm{cr}}=\frac{1}{\pi}\left(\frac{K_{\mathrm{I}}}{E}\right)^{2}\left(\frac{(n+1)^{2} E^{n} t A}{2 n \alpha_{n}^{n+1}}\right)^{2 /(n-1)} \tilde{r}_{\mathrm{c}}(\theta)
$$

where $A$ and $\tilde{r}_{\mathrm{c}}(\theta)$ are creep coefficient in Eq. (4) for the adopted power law creep equation and dimensionless function that depends on creep exponent, respectively. Herein, $\alpha_{n}$ always adopts 0.69 for $3 \leqslant n \leqslant 13$. Eq. (17) is proposed based on the RR field which was previously defined by Riedel and Rice (1980) as below.

$$
r_{\mathrm{HHR}}=\frac{1}{2 \pi}\left(\frac{K_{\mathrm{I}}}{E}\right)^{2}\left(\frac{(n+1)^{2} E^{n} t A}{2 n \alpha_{n}^{n+1}}\right)^{2 /(n-1)} F(\theta)
$$

where

$$
F(\theta)=\left[\frac{\cos ^{2} \frac{\theta}{2}\left(\eta^{\prime}+3 \sin ^{2} \frac{\theta}{2}\right)}{\tilde{\sigma}_{e}^{2}(\theta)}\right]^{(n+1) /(n-1)}
$$

in which $\eta^{\prime}=1.0$ for plane stress condition and $\eta^{\prime}=(1-2 v)^{2}$ for plane strain condition.

According to Eq. (18), the creep zone size should be the same if the SIFs of the specimens are kept as the same under transient creep. To investigate the applicability 
of Eq. (16) under the condition that the $T$-stress effect is taken into consideration, the equivalent creep zone size at both transient and extensive creep ranges under the same SIF with different $T$-stresses in the MBL model are presented in Fig. 5 and Fig. 6. It should be pointed out that the equivalent creep zone is defined as the boundary with a same level equivalent creep strain (CEEQ). The values of CEEQ shown in Fig. 5 and Fig. 6 are 0.001 corresponding to 3.6 hours and 0.005 corresponding to 10000 hours, respectively. In the aforementioned cases, the applied SIFs are kept as $142.1 \mathrm{MPa} \bullet \mathrm{mm}^{1 / 2}$ and the $T$-stresses vary differently.

By comparing the equivalent creep zone size given in Fig. 5 and Fig. 6, it can be seen that the equivalent creep zone size is influenced by the $T$-stress regardless of its creep range. Note that the applied SIFs at the outer boundary are the same, it implies that the solution given by Riedel and Rice (1980), i.e. Eq. (17), collapses under the effect of $T$-stress as the creep zone is definitely different even under the condition that the SIFs are kept to be the same. It also indicates that Eq. (16) and Eq. (17) are not correct any more if the $T$-stress effect is taken into account. It should be mentioned that there exists some differences for the creep crack tip field in the MBL model under the small $T$-stress (shown in Fig. 5) and the large $T$-stress (shown in Fig. 6). For the case of the small $T$-stress, five levels of $T$-stresses are performed, i.e. $T= \pm 18 \mathrm{MPa}, \pm 9 \mathrm{MPa}$ and $0 \mathrm{MPa}$. To investigate the large $T$-stress, five kinds of $T$-stresses are used, i.e. $T=0.0$ $\mathrm{MPa}, T= \pm 90 \mathrm{MPa}$ and $T= \pm 180 \mathrm{MPa}$. It can be found that the creep zone size and creep zone shape are totally different under both small $T$-stress condition and large $T$-stress condition as the creep zone size under large positive $T$-stress or low negative $T$-stress is larger than that of small positive $T$-stress or high negative $T$-stress. Generally, the creep zone size decreases slightly with the increase of $T$-stress level under positive $T$ stress condition and increases with the decrease of $T$-stress level under negative $T$-stress condition. Among those conditions, the creep zone size with the lowest $T$-stress, $T=-$ $180 \mathrm{MPa}$, has the largest creep zone size. The creep zone size for creep crack without $T$-stress is much smaller than that of $T=-180 \mathrm{MPa}$. The creep zone size with $T=180$ $\mathrm{MPa}$ is slightly different from that of $T=-180 \mathrm{MPa}$. The results here is very interesting as the $T$-stress under large $T$-stress condition presented here are different from the effect 
of $T$-stress on the strain hardening materials given by English and Arakere (2011).

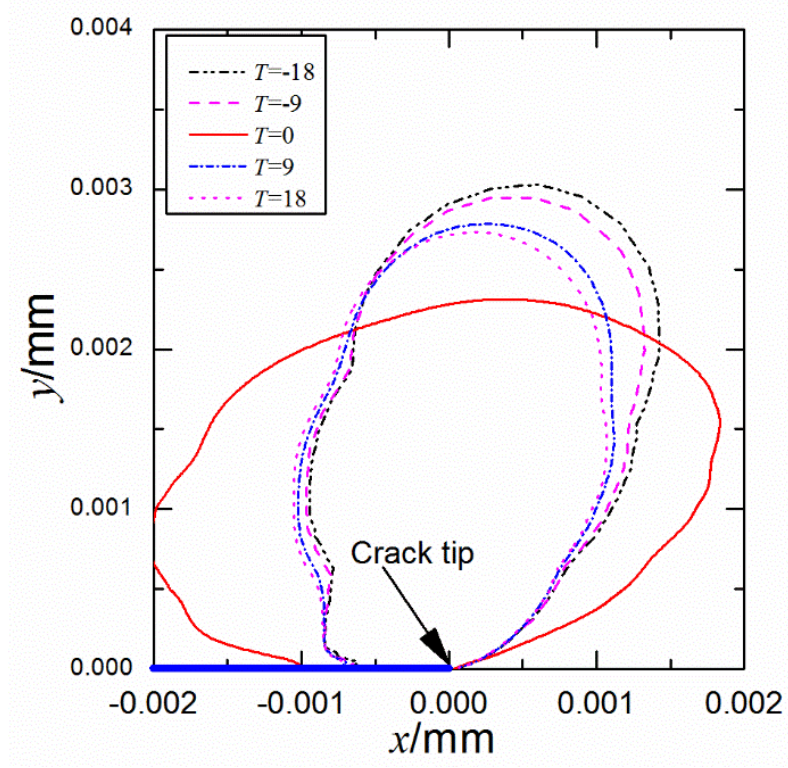

Fig. 5 Creep boundary at short creep time for the MBL model at $t=3.6$ hours with CEEQ of $0.1 \%$

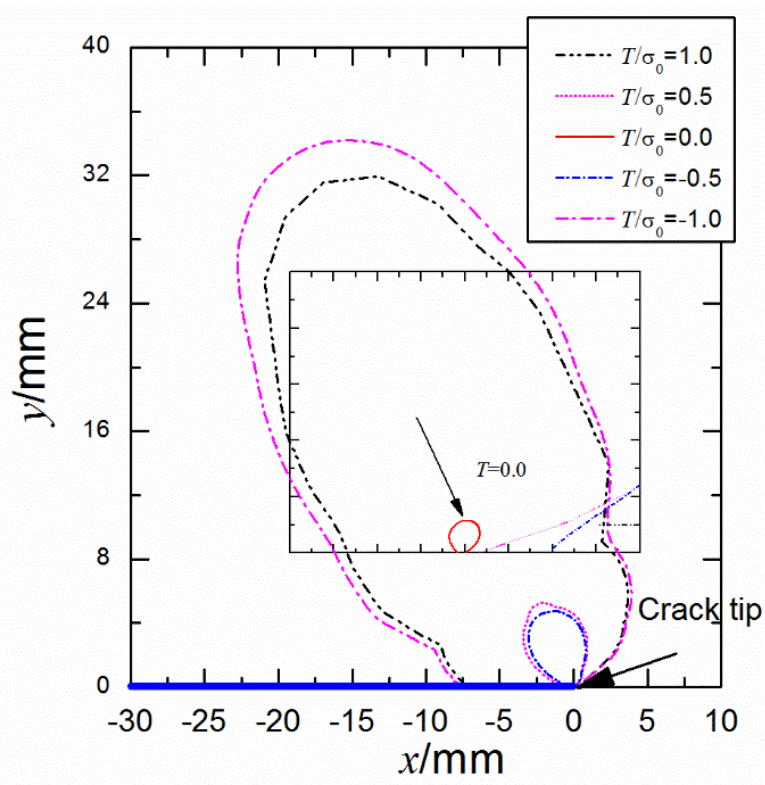

Fig. 6 Creep zone boundary at creep time of 10000 hours for the MBL model with CEEQ of $0.5 \%$

In fact, the creep zone size can be affected by two factors, i.e. SIF and $T$-stress. To evaluate which factor plays more important in the enlargement of creep zone, the creep zone size under different SIFs and $T$-stresses are given in Fig. 7. For the same SIF, the creep zone size increases promptly with the decrease of negative $T$-stress or increase of positive $T$-stress. Meanwhile, the creep zone size enlarges with the improvement of SIF. Compared with the role of SIF on the enlargement of creep zone size, the influence of $T$-stress on the creep zone size is much more remarkable. 


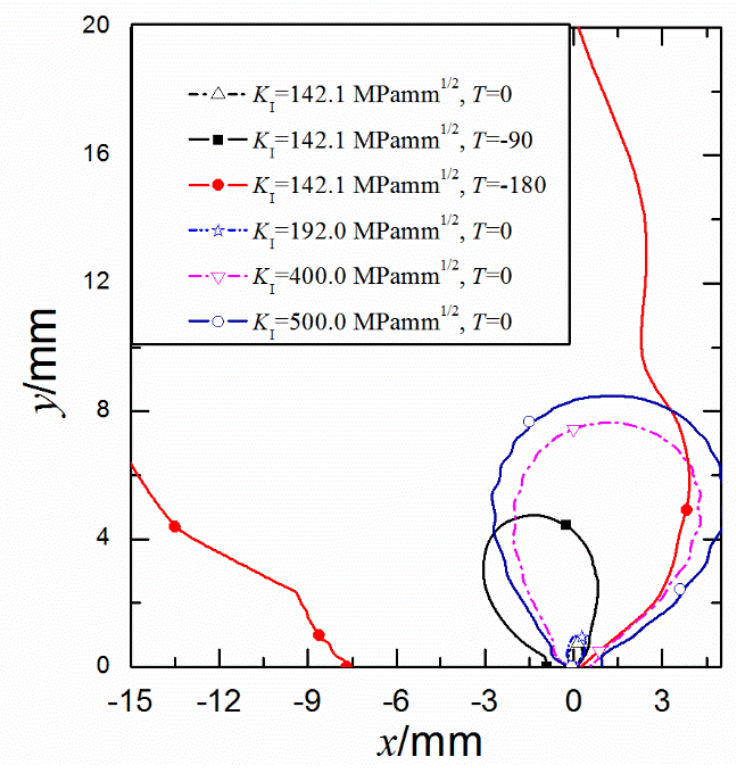

Fig. 7 Variations of creep zone size for the MBL under different $K_{\mathrm{I}}$ and $T$-stresses

\subsubsection{Equivalent creep zone for the specimens}

To clarify the relation between equivalent creep zone of the specimens and the $T$ stress level, the creep zone size of different specimens at transient and extensive creep ranges are presented in Fig. 8 and Fig. 9, respectively. The detail specimen sizes and loading conditions have been given in Table 2 . The equivalent creep strain shown in Fig. 8 and Fig. 9 are 0.001 at 3.2 hours and 0.005 at 10000 hours, respectively. Under the transient condition given in Fig. 8, the area with the same CEEQ for these specimens are totally different, and the rank of the area is CT2> CT1> CCP1> CCP2> SECP1> SECP2. Under the extensive condition given in Fig. 9, the rank of the area for the equivalent creep zone size is $\mathrm{CCP} 1>\mathrm{CT} 1>\mathrm{CCP} 2>\mathrm{SECP} 1>\mathrm{SECP} 2>\mathrm{CT} 2$. To connect the inherent relation between the $T$-stress and the equivalent creep zone size of these specimens, biaxiality ratio $C_{\mathrm{B}}$ and $T$-stress for these specimens are presented in Table 4 with the relationship given in Eq. (3). It can be seen that CCP1 specimen has the lowest $T$-stress level and the CT2 presents the highest $T$-stress level. The following two tendencies can be obtained. Firstly, the connection between the creep zone size and $T$ stress shows that the creep size zone with higher $T$-stress level has the lower creep zone size under very short creep time except for CT specimens. Secondly, the tendency that 
the case with the higher $T$-stress level contains the lower creep zone size also exists under long creep time. In general, the case with the higher $T$-stress level presents the smaller creep zone size and the case with the lower $T$-stress shows the larger creep zone size.

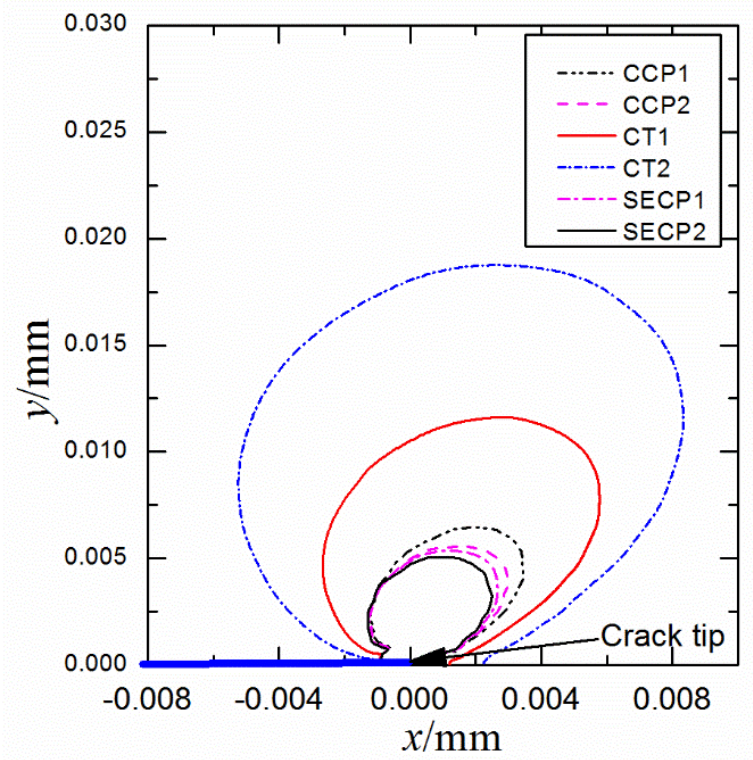

Fig. 8 Creep boundary with CEEQ of 0.001 at creep time of 3.2 hours for various specimens

Table 4 Stress biaxiality factor and $T$-stress of different specimens

\begin{tabular}{ccc}
\hline Specimen & Biaxiality factor $C_{\mathrm{B}}$ & $T$-stress $(\mathrm{MPa})$ \\
\hline SECP1 & -0.46 & -16.50 \\
SECP2 & -0.15 & -2.76 \\
CCP1 & -1.41 & -46.38 \\
CCP2 & -1.06 & -19.00 \\
CT1 & -0.33 & -10.67 \\
CT2 & 0.289 & 5.18 \\
\hline
\end{tabular}




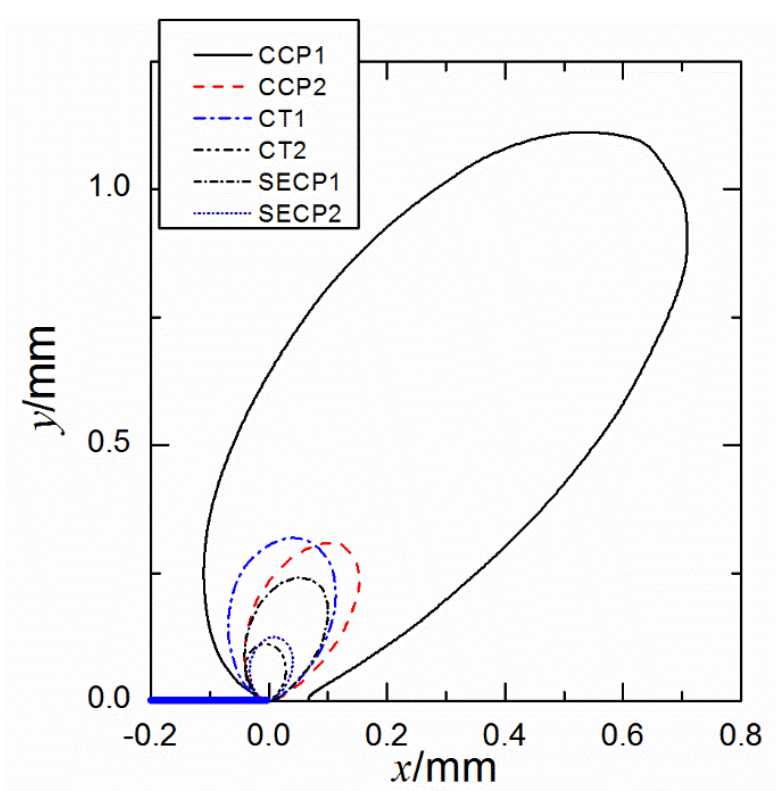

Fig. 9 Creep boundary with CEEQ of 0.005 at 10000 hours for various specimens

\subsubsection{Modification of the creep zone by considering T-stress effect}

Based on the investigations given in Section 4.2.2 and Section 4.2.3, one can find that the $T$-stress can affect the creep zone size significantly. In fact, the establishment of Eq. (17) is based on the following assumptions: small scale creep, equality of equivalent creep strain and equivalent elastic strain, and HRR type singularity. It indicates that the effect of $T$-stress was not taken into consideration in the evaluation of the creep zone size ahead of creep crack. Herein, a creep zone size is given as below by considering the effect of $T$-stress:

$$
r_{\mathrm{M}}=\left(\frac{K^{2}}{2 \pi} I_{C}\right)^{(n+1) /(n-1)}\left(\frac{C(t)}{A I_{n}}\right)^{-2 /(n-1)}\left(\frac{1}{\tilde{\sigma}_{\mathrm{e}}^{2}(\theta)}\right)^{(n+1) /(n-1)}
$$

where $I_{C}$ is a correlation factor considering the influence of $T$-stress with an approximation which can be presented as below:

$$
I_{C}=x_{1}\left(\frac{T}{\sigma_{0}}\right)^{3}+x_{2}\left(\frac{T}{\sigma_{0}}\right)^{2}+x_{2}\left(\frac{T}{\sigma_{0}}\right)^{1}+1
$$

where coefficients $x_{1}, x_{2}$ and $x_{3}$ can be obtained by FE computations. $\tilde{\sigma}_{\mathrm{e}}(\theta)$ is the dimensionless distribution function of Mises stress for creep crack tip which can be written as: 


$$
\begin{aligned}
& \tilde{\sigma}_{\mathrm{e}}(\theta)=\left[\frac{3}{2} \tilde{s}_{i j} \tilde{s}_{i j}\right]^{0.5} \\
& \tilde{s}_{i j}=\tilde{\sigma}_{i j}-\tilde{\sigma}_{k k} \delta_{i j} / 3
\end{aligned}
$$

in which $\tilde{\sigma}_{i j}$ and $\tilde{s}_{i j}$ are the angular distribution function of stress and deviatoric stress of the HRR field.

To state the $I_{\mathrm{c}}$-factor, a dimensionless parameter $\gamma=\left(I_{\mathrm{c}}\right)^{2 /(n+1)}$ is presented in Fig. 10. An empirical prediction by considering the $T$-stress is presented as below:

$$
\gamma=835.76\left(\frac{T}{\sigma_{0}}\right)^{3}+15.11\left(\frac{T}{\sigma_{0}}\right)^{2}-15.275\left(\frac{T}{\sigma_{0}}\right)+1
$$

The results show that the FE solutions agree quite closely to the predicted solutions.

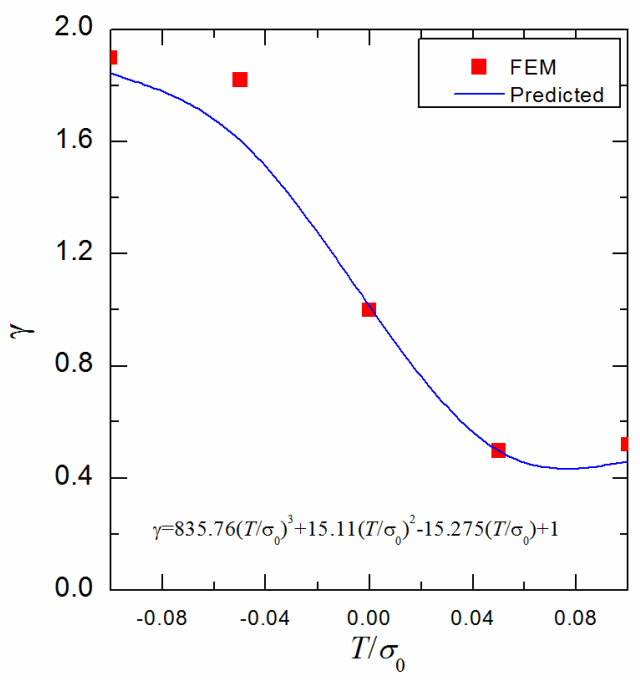

Fig. 10 Variations of $\gamma$ with $T / \sigma_{0}$

By defining the equality of the equivalent creep strain and equivalent elastic strain, the creep zone can be presented as:

$$
r_{C(\mathrm{t})}=\left(\frac{K^{2}}{2 \pi} I_{C}\right)^{(n+1) /(n-1)}\left(\frac{C(t)}{A I_{n}}\right)^{-2 /(n-1)} F^{\prime}(\theta)
$$

where $F^{\prime}(\theta)$ can be referred to Riedel and Rice (1980), and some solutions for $F^{\prime}(\theta)$ under various creep exponents are presented in Fig. 11. Herein, $r_{C(\mathrm{t})}$ is used to characterize the creep zone size of transient creep region. If the creep crack tip field is under extensive creep, $C(t)$-integral in Eq. (24) should be replaced by $C^{*}$-integral. The 
influence of $T$-stress on creep crack tip field has been included in the correlation factor $I_{\mathrm{c}}$.

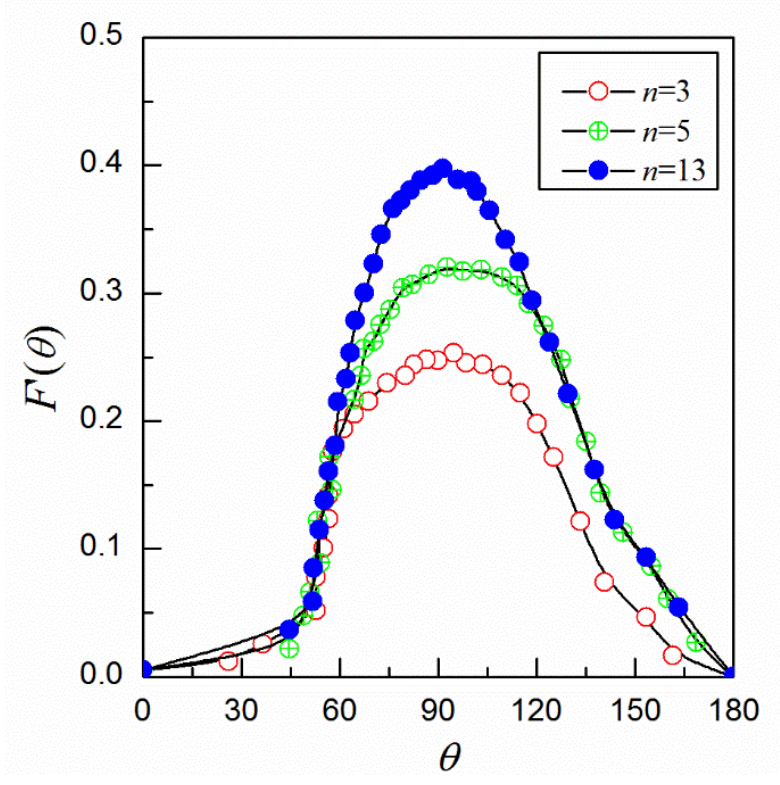

Fig. $11 F^{\prime}(\theta)$ under various creep exponents

\subsection{Influence of T-stress on creep crack tip stress field}

To investigate the effect of $T$-stress on the stress field of the creep crack tip, the following studies are performed. The opening stresses under various $T$-stresses at 10000 hours in the MBL model are presented in Fig. 12. Clearly, the opening stress near the creep crack tip satisfies the HRR singularity very well for those cases with small and moderate level $T$-stresses. Compared with the opening stress of creep crack tip for analytical HRR field, the near field of MBL model with $T=18 \mathrm{MPa}$ approaches to the analytical HRR field closely. Under these cases, it can be seen that the opening stress begins to approach to the stress field of linear elastic crack tip when the distance is far away from the the creep crack tip. For the high positive $T$-stress, e.g. $T=90 \mathrm{MPa}$, the stress field within $r<9.4 \mathrm{~mm}$ coincides with the HRR field very well, however, the opening stress within $r>9.4 \mathrm{~mm}$ does not agree well with the HRR field, and the far field linear elastic field also deviates from the theoretically predicted $K$ field. For $T=$ $180 \mathrm{MPa}$, the dominant zone of HRR field enlarges to $39.0 \mathrm{~mm}$, and the HRR 
singularity and elastic field does not agree with the predicted elastic field any more if $r>39.0 \mathrm{~mm}$ which implies there is no existence of rigorous $T$-stress at the remote far field under the condition of large positive $T$-stress.

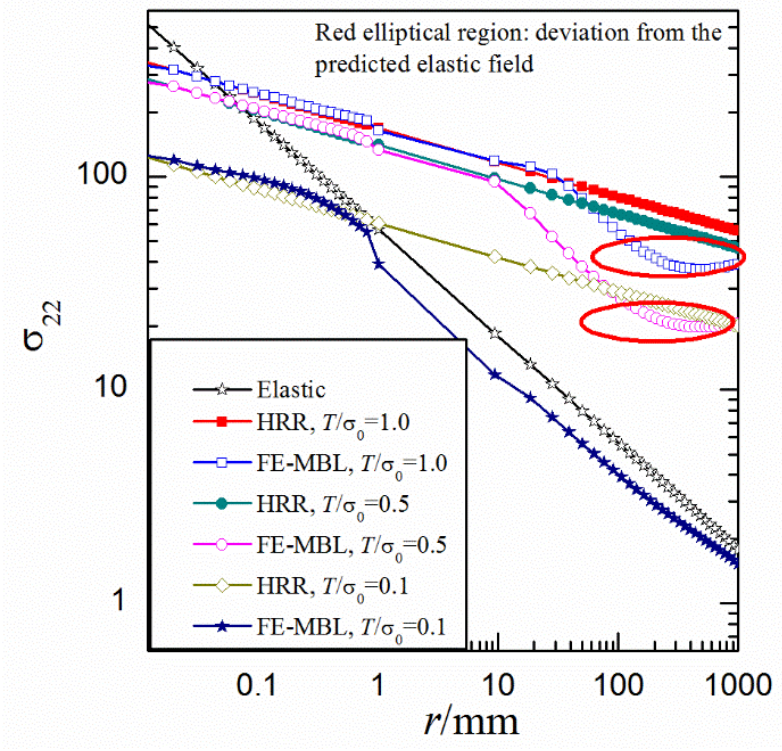

Fig. 12 Comparisons of opening stress between FE results and analytical solutions under various

$$
T \text {-stresses }
$$

Furthermore, the $T$-stress is applicable only under small and moderate creeping cases. The opening stress deviates from the theoretical solutions of the HRR field greatly under the very low negative $T$-stress. With the increase of positive $T$-stress, one can find that the HRR singularity is remained even under the very high positive $T$-stress. However, the $r^{-1 / 2}$ type singularity for the elastic field at the far field of the MBL model deviates from the theoretical solutions greatly. From the aforementioned results, it can be found that too large $T$-stress violates the elastic field and too small negative $T$ stress leads to the failure of HRR singularity as well as $r^{-1 / 2}$ singularity. It indicates that the stress field for creep crack tip field under negative $T$-stress is lower than zero. The possible reason is mainly caused by the sever creep relaxation induced by the applied displacement boundary. It implies that the MBL model is not valid under very high positive $T$-stress or very low negative $T$-stress. In order to avoid the negative opening stress, the limit of the applied $T$-stress at the remote boundary of the MBL model for creeping solids should obey $T / \sigma_{0}>-0.1$. The solutions given here are totally different with the elastoplastic crack tip field as well as the MBL in the elastoplastic 
material.

As the MBL formulation for creep crack will be collapsed under the high positive $T$-stress or the low negative $T$-stress conditions, one needs to investigate the stress field under small and moderate $T$-stress. In order to present the stress field for the MBL with small and moderate $T$-stress, the opening stresses under various $T$-stresses are presented in Fig. 13. It can be found that the opening stresses coincide with the HRR field quite well at the near field and agrees with the predicted elastic field quite good at far field under small $T$-stresses, i.e. $T=18,9,0,-9$ and -18 . This demonstrates the applicability of the MBL model with small and moderate $T$-stress under creeping conditions.

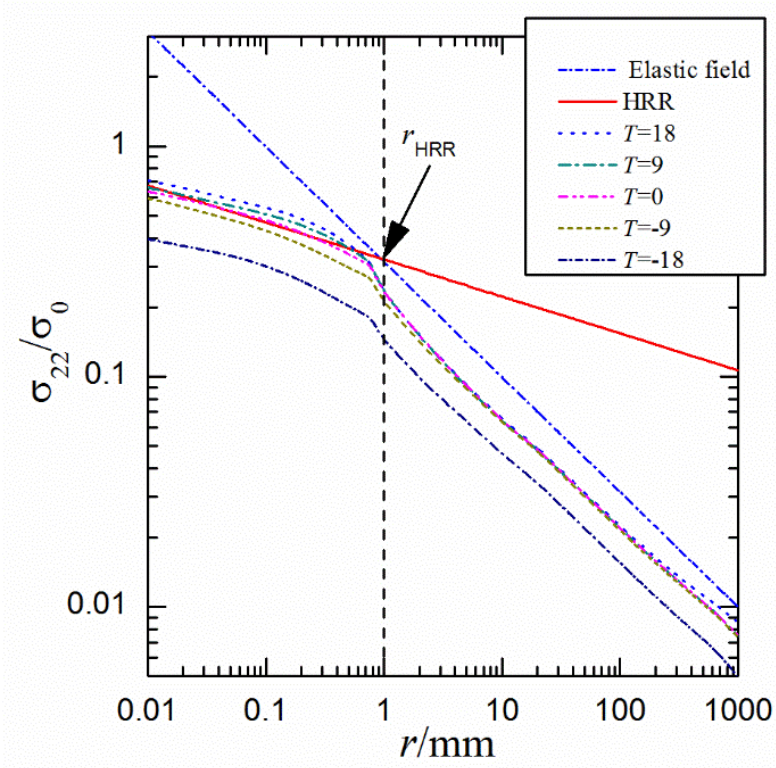

Fig. 13 Comparisons of the opening stress for the MBL under small $T$-stresses with those of HRR field and analytical elastic field 


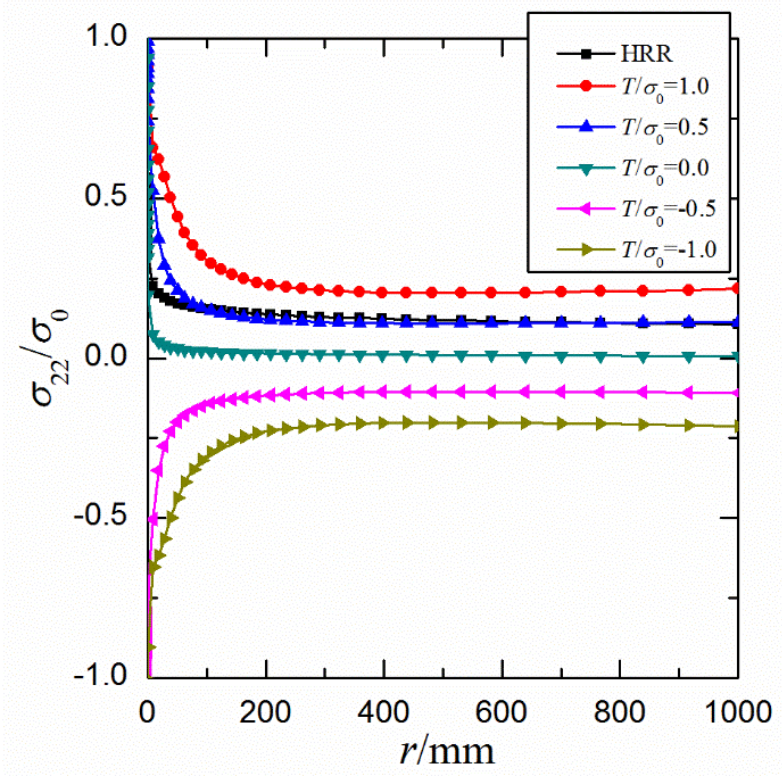

Fig. 14 Variations of opening stress under different $T$-stresses at 10000 hours for the MBL model

To reveal the effect of $T$-stress clearly, the opening stresses at 10000 hours for the MBL model under different $T$-stresses are given in Fig. 14. It can be seen that the opening stress under positive $T$-stress has the higher value than that of negative $T$-stress. In general, the opening stress improves with the increase of $T$-stress, and this tendency is very similar to the crack tip opening stress of elastoplastic material given by English and Arakere (2011). However, the opening stress of near crack tip drops promptly at lower negative $T$-stress. This phenomenon is rather different from that of elastoplastic case presented by English and Arakere (2011). The solutions shown in Fig. 14 also demonstrates the rationality of the conclusion which has been discussed at the start of this section.

\subsection{Influence of T-stress on Constraint}

As stated in Section 4.3, the stress field of creep crack can be affected by the $T$ stress. Hence, it is necessary to connect the constraint effect with $T$-stress for creep crack tip field. Due to the difference of creep range, the influences of $T$-stress on the crack tip field under transient creep and extensive creep are discussed in the follows. 


\subsubsection{Transient creep}

Under elastoplastic condition, there exists the following famed relation between $Q$ parameter and $T$-stress presented in Eq. (25) which was proposed by O'Dowd and Shih (1994).

$$
Q=a_{1}\left(\frac{T}{\sigma_{0}}\right)+a_{2}\left(\frac{T}{\sigma_{0}}\right)^{2}+a_{3}\left(\frac{T}{\sigma_{0}}\right)^{3}
$$

in which the coefficients $a_{i}(i=1,2,3)$ are related with specific specimen geometry and loading level, and they can be determined by curve fitting. It can be seen that the $Q$-parameter can be described by a polynomial expression of $T$-stress under elastoplastic case.

In order to validate the applicability of the $Q-T$ relation given in Eq. (25) for the creep crack tip field under transient creep range, the variations of $Q$-parameter in the MBL model under various $T$-stresses at 10000 hours are given in Fig. 15. Herein, the opening stress under $T=0$ with small scale creep is selected as the reference stress field. It should be noted that the $Q$-parameters are calculated at different distances from creep crack tip in the MBL model. With the calculated $Q$-parameter, one can obtain the coefficients of Eq. (25) which are presented in Table 5. In general, the $Q$-parameter in the MBL model under transient creep can be predicted as a polynomial function of the $T$-stress, which is very similar to the elastoplastic condition. Meanwhile, it has to confess that the $Q$-parameter under transient creep is highly dependent on the radial distance away from crack tip field.

Table 5 Coefficients of Eq. (25) for $Q-T$ relation of the MBL model shown in Fig. 15

\begin{tabular}{cccc}
\hline Distance $(\mathrm{mm})$ & $a_{1}$ & $a_{2}$ & $a_{3}$ \\
\hline$r=0.02$ & 116.090 & -23.495 & 1.930 \\
$r=0.11$ & 54.740 & -5.693 & 0.645 \\
$r=0.54$ & 30.687 & -4.204 & 0.089 \\
$r=1.00$ & 28.133 & -5.339 & 0.550 \\
\hline
\end{tabular}




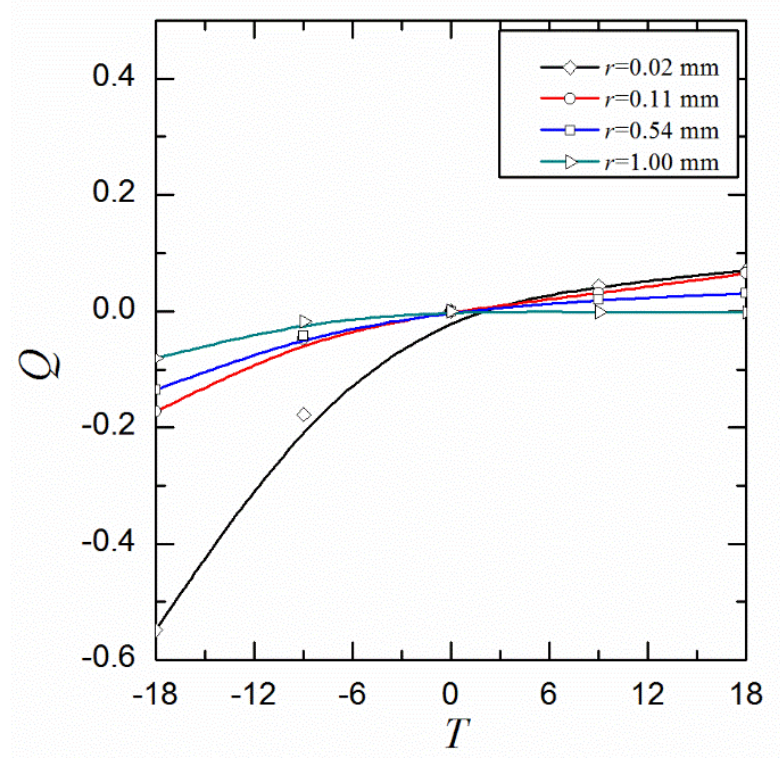

Fig. 15 Variations of $Q$-parameter for the MBL model under different $T$-stresses with $K_{\mathrm{I}}=142.1$

$$
\mathrm{MPa} \bullet \mathrm{mm}^{1 / 2}
$$

\subsubsection{Extensive creep}

Due to the limitation, the MBL model used previously is not suitable to be used to characterize the constraint effect of the crack tip field under the extensive creep. To overcome this shortage, the specimens presented in Table 2 are adopted to perform the analysis under extensive creep. Herein, the opening stress under $T=0$ is adopted as the reference stress field. Thereafter, the $Q$-parameter is presented as following:

$$
Q=\frac{\sigma_{22}-\sigma_{22}^{\mathrm{SSC}, T=0}}{\sigma_{0}}
$$

where $\sigma_{22}^{\mathrm{ssc}, T=0}$ represents the opening stress under small scale creep with $T=0$. Under extensive creep, the stress of small scale creep with $T=0$ can be represented by the opening stress of the HRR field as that defined by Eq. (5). The variations of the opening stress with creep time for different specimens are given in Fig. 16. Due to the creep relaxation, it can be seen that the opening stress drops greatly with the increase of creep time. 


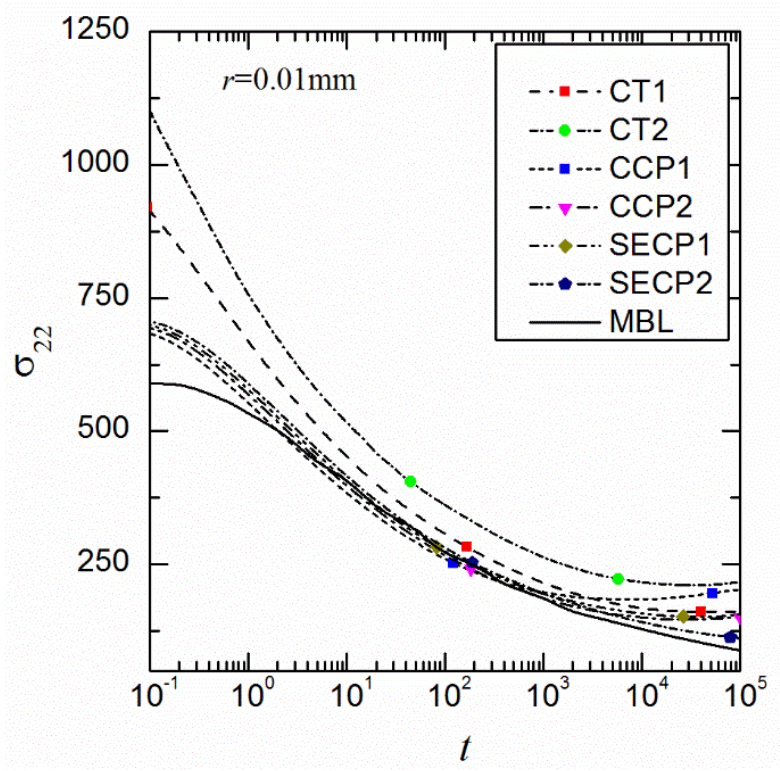

Fig. 16 Variations of opening stress for different specimens with the increase of creep time

With Eq. (26), the $Q$-parameter for different specimens at 10000 hours along the radial distance away from creep crack tip are given in Fig. 17. Clearly, the $Q$-parameters of different specimens are generally independent of the radial distance and nearly kept as a constant. If one takes the $T$-stress is taken into consideration, it can be seen that the $Q$-parameter decreases with the reduction of the $T$-stress. It implies that the $Q$ parameter is related with the $T$-stress even under extensive creep.

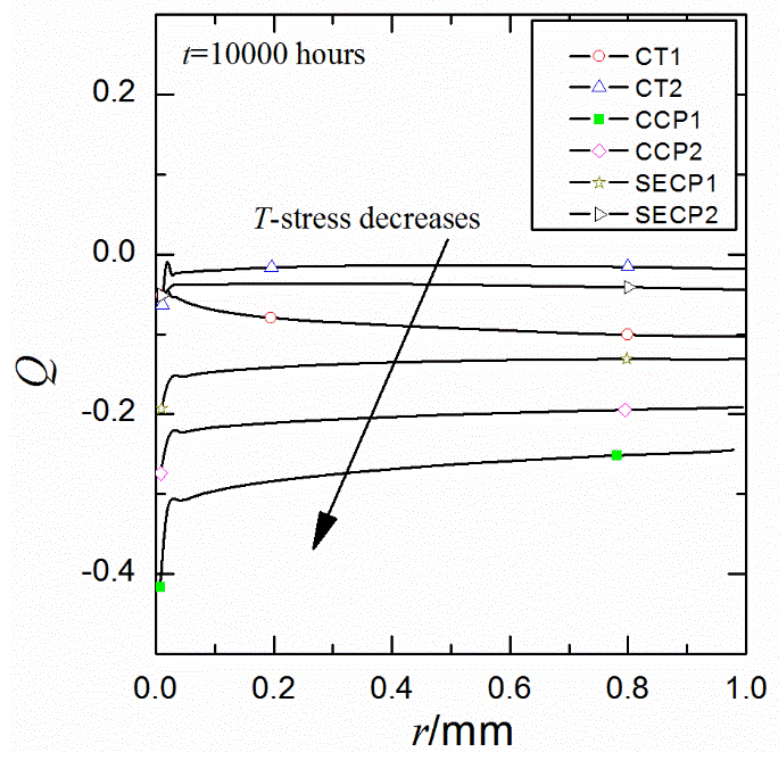

Fig. 17 Variations of $Q$-parameter for different specimens at 10000 hours 


\subsubsection{Inherent connections between T-stress and Q-parameter in various specimens}

According to the analyses given in Section 4.4.1 and Section 4.4.2, it can be seen that the $Q$-parameter should be related with the level of $T$-stress. In order to investigate the inherent connection between $T$-stress and $Q$-parameter for creep crack tip field, CCP, SECP and CT specimens with different crack depths are discussed in the follows. Note that the constraint effect is not only dependent on the $T$-stress level, but also dependent on the crack depths as well as loading level. In order to study the effect of loading level, each kind of specimen with six different loadings are adopted.

Stress biaxiality, $T$-stress, and creeping fracture parameters for the $\mathrm{CCP}$ specimens are presented in Table 6. To denote the different characteristics of CCP specimen, these conditions are denoted from L1 to L6. Meanwhile, the stress biaxiality are kept to be 1.41 for L1, L2 and L3. The stress biaxiality for L4, L5 and L6 are kept to be -1.06. Among those cases presented in Table 6, it can be found that the L3 has the lowest $T$ stress and $\mathrm{L} 4$ has a rather higher $T$-stress. From Table 6 , the $C^{*}$-integral heightens with the increase of the SIF under the same stress biaxiality. By comparing L2 with L5, an interesting phenomenon is that the $C^{*}$-integral does not increase with the improvement of the SIF but heightens with the increase of $T$-stress.

Table 6 Fracture parameters for CCP specimens

\begin{tabular}{cccccc}
\hline No. & Biaxiality $C_{\mathrm{B}}$ & $\begin{array}{c}T \text {-stress } \\
(\mathrm{MPa})\end{array}$ & $\begin{array}{c}C^{*} \text {-integral } \\
(\mathrm{MPa} \bullet \mathrm{mm} / \mathrm{hour})\end{array}$ & $\begin{array}{c}\mathrm{SIF} \\
\left(\mathrm{MPa} \bullet \mathrm{mm}^{1 / 2}\right)\end{array}$ & $a / W$ \\
\hline L1 & -1.41 & -81.35 & 0.00243 & 248.7 & 0.15 \\
L2 & -1.41 & -101.70 & 0.00975 & 311.2 & 0.15 \\
L3 & -1.41 & -122.00 & 0.0304 & 373.5 & 0.15 \\
L4 & -1.06 & -50.35 & 0.000776 & 266.3 & 0.5 \\
L5 & -1.06 & -62.94 & 0.00311 & 332.8 & 0.5 \\
L6 & -1.06 & -75.72 & 0.00969 & 399.4 & 0.5 \\
\hline
\end{tabular}

The variations of $Q$-parameter for CCP specimens at 100000 hours are given in Fig. 18. Herein, the normalized distance $\bar{r}$ defined in Eq. (11) is adopted. One can find that $Q$-parameter decreases with the reduction of the $T$-stress which implies that the loss of constraint heightens with the decrease of the $T$-stress. Generally, the $Q$-parameters 
obtained in CCP specimens are nearly independent on the normalized distance except the very near region close to the creep crack. Compared with the shallow cracked CCP specimens (L1, L2 and L3), the deep cracked CCP specimens (L4, L5 and L6) present the higher constraint level.
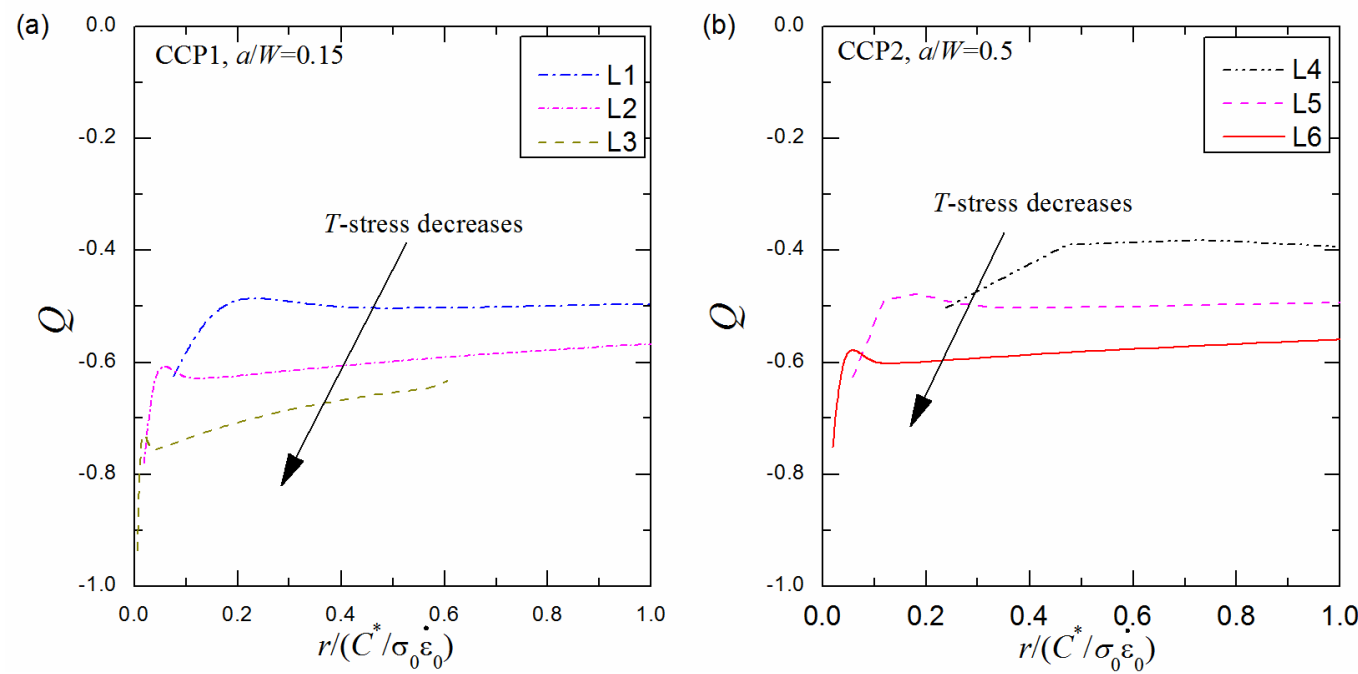

Fig. 18 Variations of $Q$ with normalized distance under different loadings for CCP specimens (a) shallow crack and (b) deep crack

The variations of $Q$-parameter along the true distance from creep crack tip for CCP specimens are given in Fig. 19. Compared with Fig. 18, the true distance is used in Fig. 19 instead of normalized distance. It can be seen that the $Q$-parameters for both shallow and deep cracked CCP specimens present the similar tendencies to those shown in Fig. 18. It indicates that the tendencies of $Q$-parameter for creep crack are not dependent on whether the use of true distance or normalized distance. This phenomenon under creeping case is very different from that of elastoplastic case in which the normalized distance was always used for the characterization of constraint effect for crack tip stress field in elastoplastic material. In fact, the true distance was used in many investigations (Wang et al., 2010; Zhao et al., 2015b) to characterize the constraint effect for creep crack tip field. Some researchers (Tan et al., 2014) even connected the physical fracture with the true distance as the fracture process zone is related with the actual distance away from creep crack tip. In general, the comparison between Fig. 18 and Fig. 19 shows that the tendencies of the case with normalized distance and true distance are very similar. The solutions presented with actual distance are rather clear and good. 

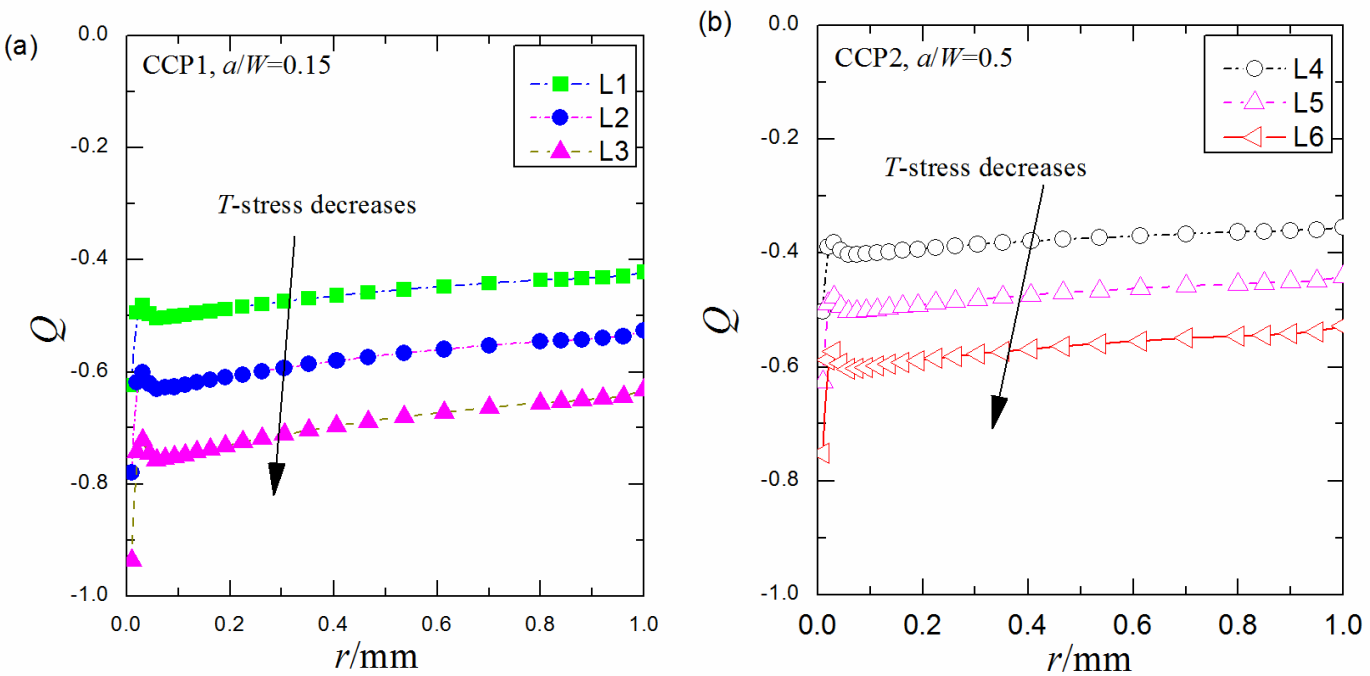

Fig. 19 Variations of $Q$ along radial direction for CCP specimens at 10000 hours

The stress biaxiality, $T$-stress as well as $C^{*}$-integral of SECP specimens under different loadings are are presented in Table 7 . Herein, two stress biaxiality with two crack depths are adopted. The stress biaxiality for the group numbered with W1, W2 and $\mathrm{W} 3$ is remained as -0.46 , and the group numbered with $\mathrm{W} 4$, W5 and W6 is kept as -0.15. The $Q$-parameters for SECP specimens at 10000 hours are presented in Fig. 20. It can be seen that the $Q$-parameter decreases with the reduction of $T$-stress, which presents the similar tendency to that of CCP specimen. Compared with the shallow cracked SECP specimens, the deep cracked SECP specimens obtain the higher constraint level. With the increase of loading, the constraint level characterized by $Q$ parameter becomes lower for both shallow and deep cracked SECP specimens. The tendencies shown in Fig. 20 are very similar to those solutions of CCP specimens.

Table 7 Fracture parameters for SECP specimens

\begin{tabular}{cccccc}
\hline No. & Biaxiality $C_{\mathrm{B}}$ & $\begin{array}{c}T \text {-stress } \\
(\mathrm{MPa})\end{array}$ & $\begin{array}{c}C^{*} \text {-integral } \\
(\mathrm{MPa} \bullet \mathrm{mm} / \mathrm{hour})\end{array}$ & $\begin{array}{c}\mathrm{SIF} \\
\left(\mathrm{MPa} \bullet \mathrm{mm}^{1 / 2}\right)\end{array}$ & $a / W$ \\
\hline W1 & -0.46 & -22.38 & $7.85 \mathrm{E}-05$ & 192.7 & 0.125 \\
W2 & -0.46 & -27.98 & 0.000315 & 240.9 & 0.125 \\
W3 & -0.46 & -33.58 & 0.000979 & 289.1 & 0.125 \\
W4 & -0.15 & -2.76 & $8.75 \mathrm{E}-07$ & 142.1 & 0.5 \\
W5 & -0.15 & -4.35 & $9.65 \mathrm{E}-06$ & 223.8 & 0.5 \\
W6 & -0.15 & -8.70 & 0.000674 & 447.5 & 0.5 \\
\hline
\end{tabular}



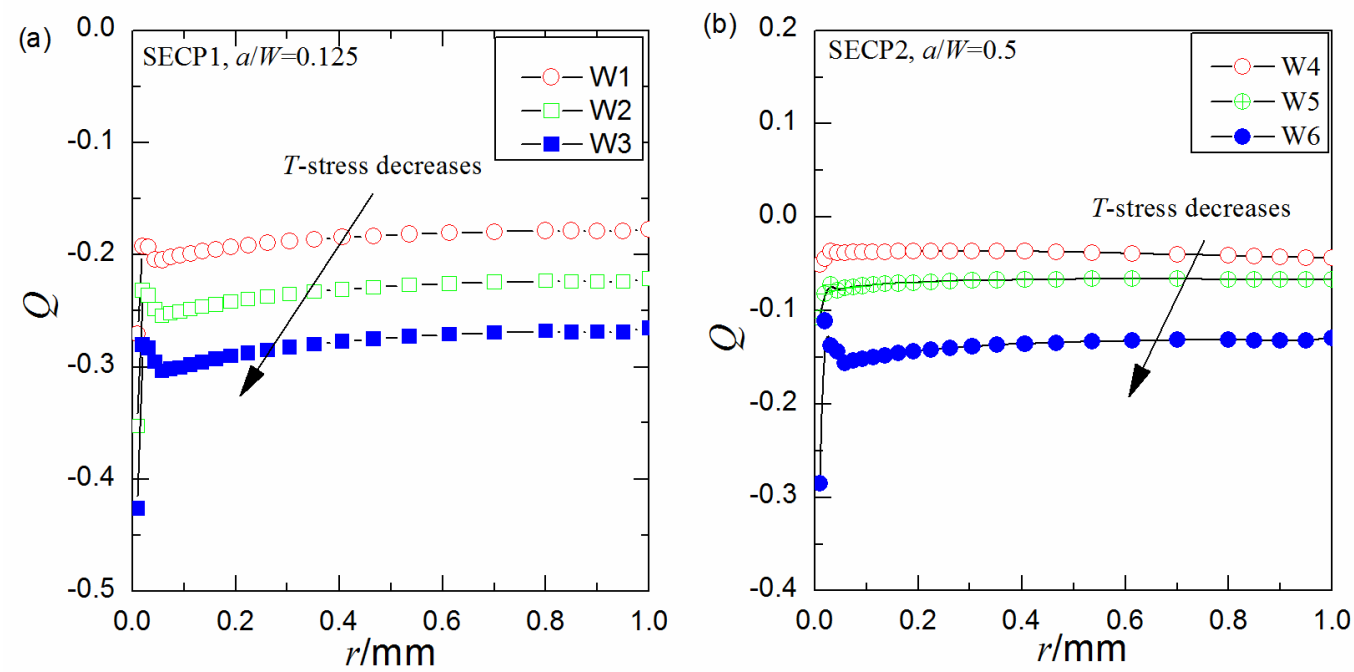

Fig. 20 Variations of $Q$ along radial direction for SECP specimens at 10000 hours

The stress biaxiality, $T$-stress and creeping fracture parameters for CT specimens are presented in Table 8. Six CT specimens with shallow and deep crack depths are adopted here. As for CT specimen, two biaxiality levels are presented in Table 8, i.e. 0.33 and 0.289 . For shallow cracked CT specimens, denoted with H1, H2 and H3, Tstresses are negative. For deep cracked CT specimens, denoted with H4, H5 and H6, the $T$-stresses here are positive.

Compared with the other specimens, the tendencies for $Q$-parameters of shallow cracked and deep cracked CT specimens are rather different. For shallow cracked CT specimens, denoted with $\mathrm{H} 1, \mathrm{H} 2$ and $\mathrm{H} 3$, the $Q$-parameter decreases with the reduction of $T$-stress. Furthermore, the $Q$-parameters for shallow cracked CT specimens rely on the distance away from creep crack tip field. For deep cracked CT specimens, denoted with $\mathrm{H} 4, \mathrm{H} 5$ and $\mathrm{H} 6$, the $Q$-parameters decrease with the increase of the $T$-stress. Generally, the $Q$-parameters here are not dependent on the distance for deep cracked CT specimens. It can be found that the constraint effect for deep cracked CT specimens are different from those of other specimens.

From the comparison of the $T$-stress level between the shallow and deep cracked specimens, one can find that the $T$-stress for deep cracked CT specimens are quite different from the other specimens as the deep cracked CT specimens have the positive $T$-stress. It implies that the effect of $T$-stress on the cracked specimens in creeping solids is important. There should exist the inherent connections between $T$-stress and 
constraint parameter $Q$ for the creep crack.

Table 8 Fracture parameters for CT specimens

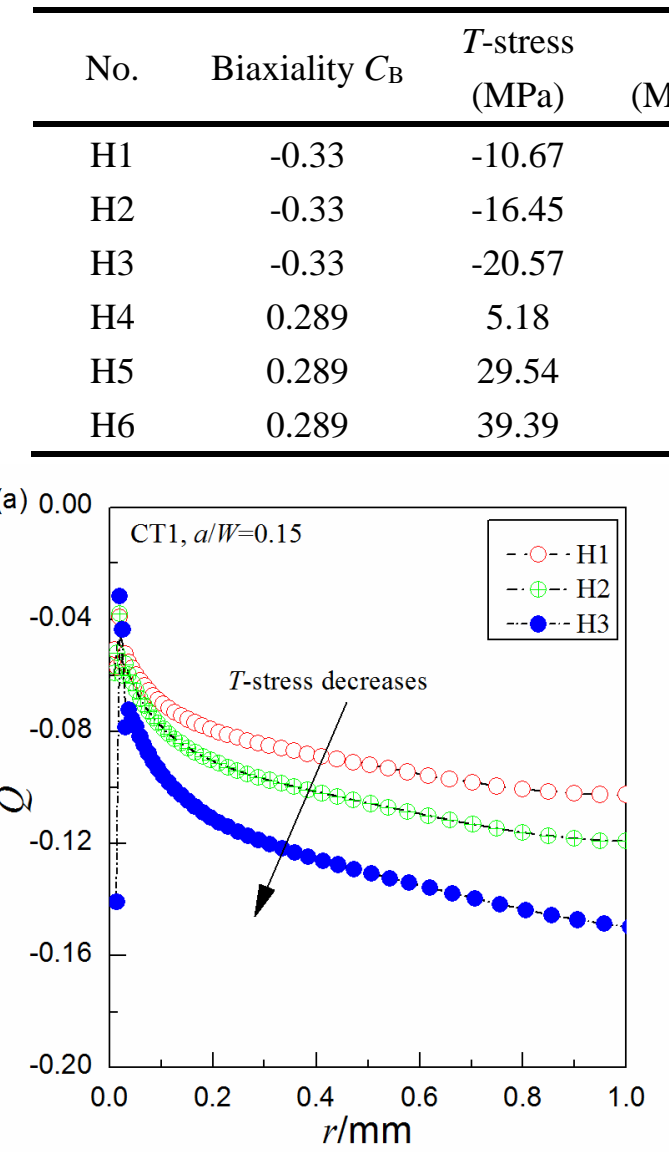

\begin{tabular}{ccc}
$\begin{array}{c}C^{*} \text {-integral } \\
\text { MPa॰mm/hour })\end{array}$ & $\begin{array}{c}\text { SIF } \\
\left(\mathrm{MPa} \bullet \mathrm{mm}^{1 / 2}\right)\end{array}$ & $a / W$ \\
\hline $7.13 \mathrm{E}-06$ & 142.1 & 0.15 \\
$1.60 \mathrm{E}-05$ & 232.5 & 0.15 \\
$6.34 \mathrm{E}-05$ & 290.7 & 0.15 \\
$3.33 \mathrm{E}-05$ & 142.1 & 0.5 \\
0.000414 & 423.7 & 0.5 \\
0.00249 & 565.0 & 0.5 \\
\hline
\end{tabular}

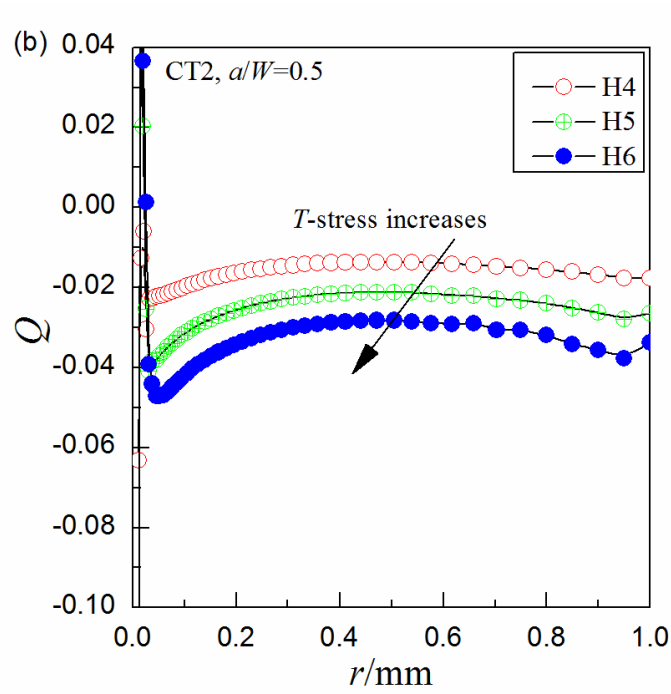

Fig. 21 Variations of $Q$ along radial direction for CT specimens at 10000 hours

\subsection{Difference of crack tip field between small strain and finite strain}

It should be noted that the HRR theory and the high order term theorey are based on the small strain assumption. However, the crack tip field under creeping condition may suffer the large deformation (or finite strain deformation) as the creep strain accumulates with the increase of the creep time. In this section, the stress fields for the MBL as well as CCP specimens under the small strain and finite strain deformation are discussed and compared.

\subsubsection{MBL model}

To verify the accuracy of the model, the SIF calculated by FE analyses are 
compared with the applied SIF at the outer boundary of the MBL model. Four models are adopted, and the SIF and crack type can be seen in Table 9. The symbols "SSL", "SSH", "FSL" and "FSH" in Table 9 represent the crack type under small strain mode with low SIF, the crack type under small strain with high SIF, the crack type under finite strain mode with low SIF and the crack type under finite strain with high SIF, respectively. The low SIF and high SIF for the small strain and finite strain deformation are remained as $187 \mathrm{MPa} \cdot \mathrm{mm}^{1 / 2}$ and $400 \mathrm{MPa} \cdot \mathrm{mm}^{1 / 2}$, respectively. All the relative errors presented in this study are less than $6.5 \%$.

Table 9 Comparisons of SIF and $J$-integral for the MBL model with different deformation modes

\begin{tabular}{ccccccc}
\hline No. & $\begin{array}{c}\text { Crack depth } \\
(\mathrm{mm})\end{array}$ & $\begin{array}{c}\text { Applied } K_{\mathrm{I}} \\
\left(\mathrm{MPa} \bullet \mathrm{mm}^{1 / 2}\right)\end{array}$ & $\begin{array}{c}\text { Near tip } \\
J_{\mathrm{e}}(\mathrm{N} / \mathrm{mm})\end{array}$ & $\begin{array}{c}\text { SIF by } \\
J_{\mathrm{e}}(\mathrm{N} / \mathrm{mm})\end{array}$ & $\begin{array}{c}\text { Crack } \\
\text { type }\end{array}$ & $\begin{array}{c}\text { Relative } \\
\text { Error }(\%)\end{array}$ \\
\hline MBL-A1 & 1000 & 186.7 & 0.3148 & 198.4 & SSL & 6.27 \\
MBL-A2 & 1000 & 399.4 & 1.441 & 424.4 & SSH & 6.26 \\
MBL-A3 & 1000 & 187.1 & 0.2829 & 188.0 & FSL & 0.481 \\
MBL-A4 & 1000 & 399.8 & 1.2920 & 401.9 & FSH & 0.525 \\
\hline
\end{tabular}
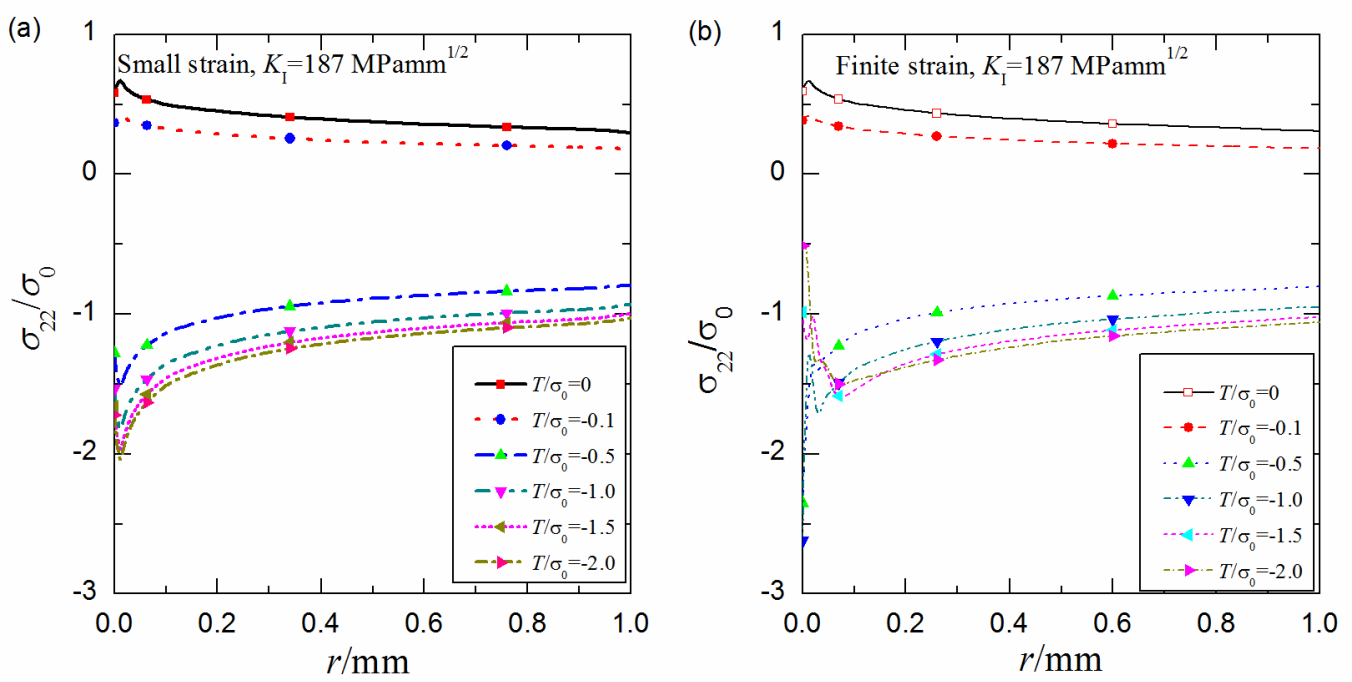

Fig. 22 Variations of opening stress for the MBL under (a) small strain and (b) finite strain under low loading conditions

The oepning stresses along $\theta=0^{\circ}$ for low loading condition under various $T$-stresses are given in Fig. 22, which shows the tendencies of opening stress under botsh small strain and finite strain deformation with low SIF at 10000 hours. Results show that the opening stress drops greatly with the decrease of $T$-stress and becomes negative as if $T / \sigma_{0}<-0.1$. The variations of the opening stress for high loading condition at 10000 
hours under various $T$-stresses with samll strain and large strain deformation are given in Fig. 23. It can be seen that the effect of $T$-stress on the creep crack tip field presents to be the same tendency regardless of the deformation mode and the loading level.
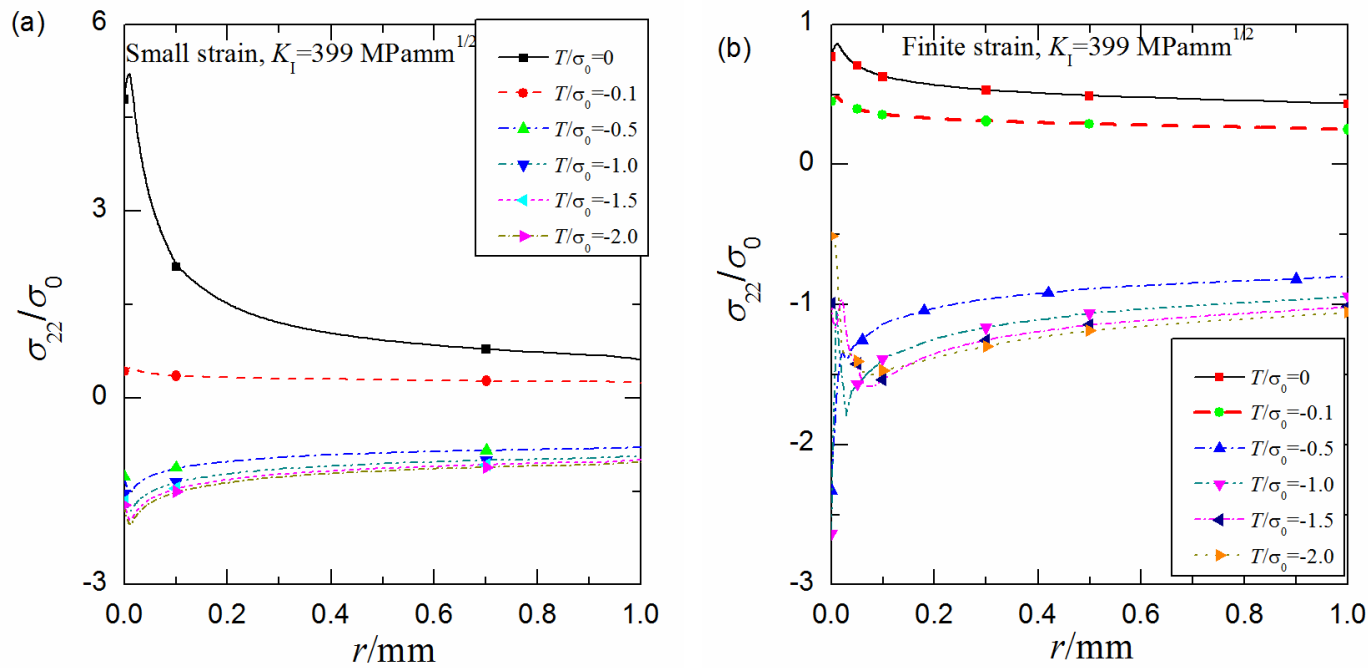

Fig. 23 Variations of opening stress for the MBL under (a) small strain and (b) finite strain under high loading conditions

\subsubsection{CCP specimen}

To investigate the effect of finite strain deformation on the creep crack tip field, four cases with different loading levels and different deformation modes for CCP specimens shwon in Table 10 are presented. Herein, SSS, SSD, FSS and FSD represent the small strain deformation with shallow crack, small strain deformation with deep crack, finite strain mode with shallow crack and the finite strain mode with deep crack for CCP specimens, respectively. To verify the accuracy of the FE meshes, the SIF calculated by ABAQUS is compared with the empirical solutions given by Brown (1966). Results show that the SIF computed with FE coincides with the Brown's solution very well. Hence, the FE meshes are verified to be fine enough.

The variations of opening stress at 10000 hours for the four CCP specimens defined in Table 10 are presented in Fig. 24. It can be found that the opening stress of CCP-A1 specimen presents the same tendency compared with that of CCP-A3 specimen regardless of the small strain deformation and finite strain deformation. However, the differences of opening stresses between $\mathrm{CCP}-\mathrm{A} 2$ specimen and $\mathrm{CCP}-\mathrm{A} 4$ specimen are 
remarkable, which have shown in Fig. 24. It can be found from the solutions that the main differenc for the opening stress between small strain and large strain on the stress distribution is kept in $r<1 \mathrm{~mm}$ ahead of creep crack, which is attributed as the blunting affected zone.

Table 10 Comparisons of SIF and $J$-integral for CCP specimens under small strain and finite strain deformation modes

\begin{tabular}{|c|c|c|c|c|c|}
\hline No. & $a / W$ & $\begin{array}{l}K_{\mathrm{I}} \text { ABAQUS } \\
\left(\mathrm{MPa} \cdot \mathrm{mm}^{1 / 2}\right)\end{array}$ & $\begin{array}{c}\text { Brown } \quad(1966) \\
\left(\mathrm{MPa} \bullet \mathrm{mm}^{1 / 2}\right)\end{array}$ & $\begin{array}{l}\text { Crack } \\
\text { type }\end{array}$ & $\begin{array}{l}\text { Relative } \\
\text { Error (\%) }\end{array}$ \\
\hline CCP-A1 & 0.15 & 186.7 & 187.49 & SSS & 0.42 \\
\hline CCP-A2 & 0.5 & 399.4 & 397.72 & SSD & 0.42 \\
\hline CCP-A3 & 0.15 & 187.1 & 187.49 & FSS & 0.21 \\
\hline CCP-A4 & 0.5 & 399.8 & 397.72 & FSD & 0.02 \\
\hline
\end{tabular}
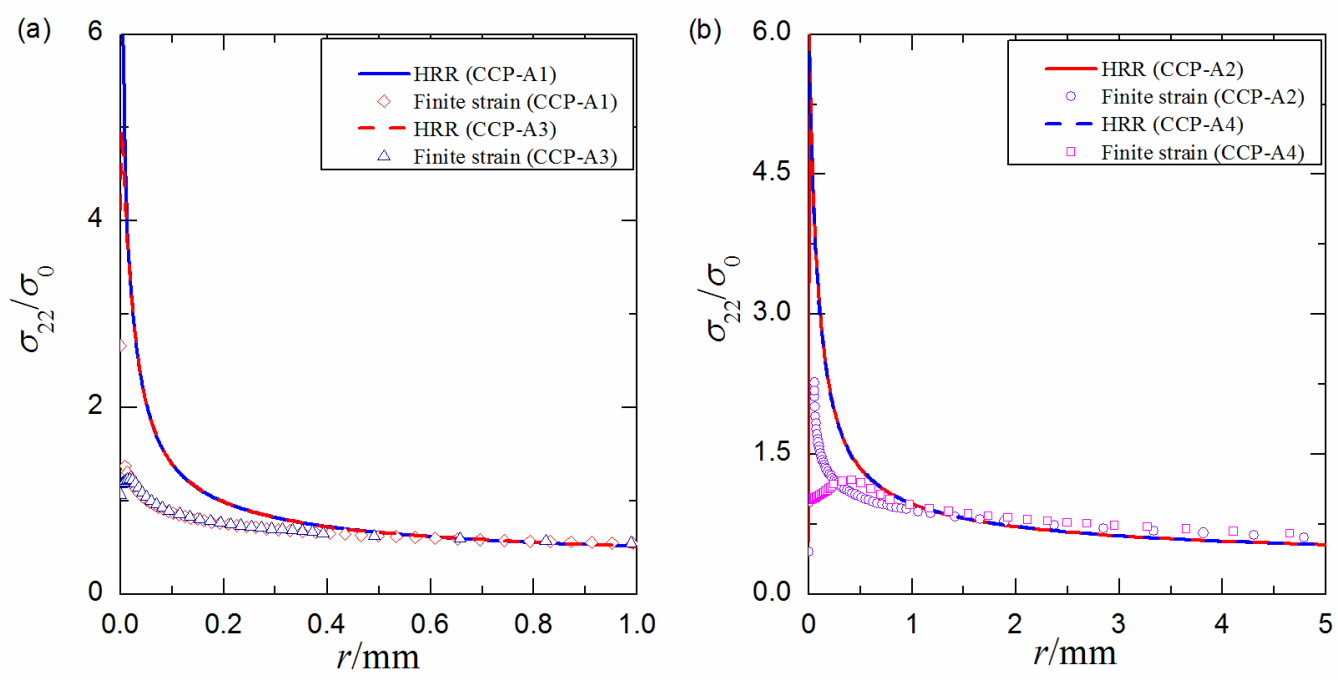

Fig. 24 Variations of opening stresses for CCP specimens under (a) low loading conditions and (b) high loading conditions

Fig. 25 is presented to state the distributions of creep strain for creep crack under different deformation modes, which shows that the distribution of creep strain is different under small strain and finite strain deformation. Due to the HRR singularity, the strain near the crack tip under the samll strain mode is much higher than that of finite strain mode. Hence, the accumulation of creep strain under samll strain mode is much higher than that of finite strain mode, and the dominant region of the finite strain deformation is less than $0.1 \mathrm{~mm}$. 


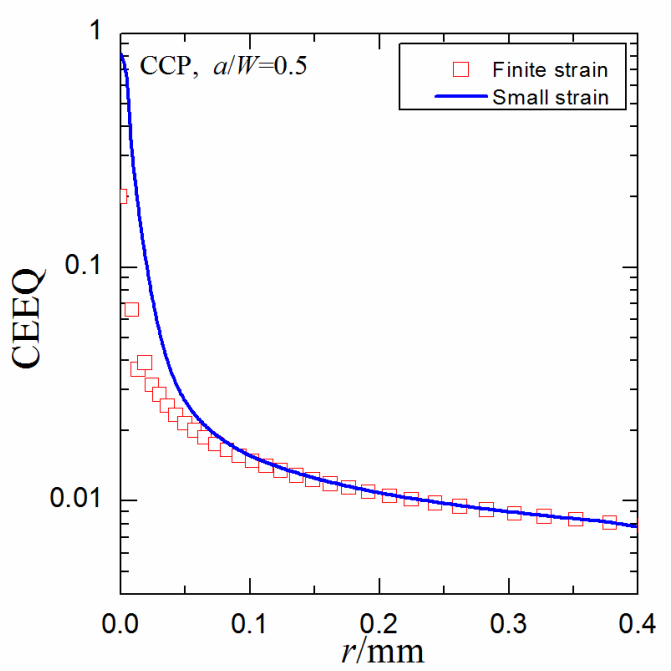

Fig. 25 Comparisons of CEEQ along radial direction for crack tip under small strain and finite strain deformation for CCP specimens

\section{Concluding remarks}

The influence of $T$-stress on mode I creep crack tip field is investigated in this paper. Based on the numerical computations and analyses, the concluding remarks are drawn as below:

1) A numerical method to determine the $T$-stress is presented for the creep crack tip field under mode I loading. The MBL model is validated to be applicable under small and moderate level of $T$-stress. From the investigations of the MBL model, it is found that the HRR singularity for power-law creep is violated under low negative $T$-stress, i.e. $T / \sigma_{0}<-0.1$. The MBL model is not applicable when the $T$ stress level is too high or $T$-stress is too low, i.e. $\left|T / \sigma_{0}\right|>0.1$.

2) The effect of $T$-stress on the creep zone for the mode I creep crack is investigated and presented. Both the creep zone size and the creep zone shape are influenced by the $T$-stress significantly. The creep zone defined previously without considering the effect of $T$-stress is demonstrated to be defective as the creep zone under the effect of $T$-stress cannot be estimated accurately. An estimation formula to evaluate the modified creep zone size is proposed by considering the effect of $T$-stress. 
3) The inherent connection between constraint parameter $Q$ and $T$-stress is studied. Under transient creep, the constraint effect is verified to be influenced by the $T$ stress. The constraint parameter $Q$ can be still described by the three order polynomial of $T / \sigma_{0}$ for small scale or moderate scale creep. However, $Q$ parameter is found to be path-dependent under transient creep. Under extensive creep, $Q$ decreases with the reduction of the $T$-stress level for those specimens $(\mathrm{CCP}$, SECP and CT) with negative $T$-stress regardless of crack depths. For positive $T$ stress, $Q$ parameter is different as it decreases with the increase of the $T$-stress, e.g. deep cracked CT specimen. The $Q$-parameter is nearly path independent for CCP, SECP specimens under extensive creep.

4) The difference of the crack tip field between small strain deformation and finite strain deformation under low and high loading conditions are also discussed. Under the finite strain deformation condition, the opening stress under high loading level is much less than that of small strain deformation condition. The main discrepancy region between small strain and finite strain in the analysed case is within $r<1 \mathrm{~mm}$ for CCP specimen.

The investigations presented in this paper can improve the in-depth understanding of the $T$-stress effect on the crack tip field under both transient creep and extensive creep. Furthermore, the discussion on the inherent connection between $T$-stress and constraint effect for creep crack under mode I loading condition can further inspire the interest and attention on the study on the inherent connection relations between different constraint parameters for creep crack.

\section{Acknowledgement}

The authors would like to thank Prof. Yuh-Jin Chao and Prof. M.R. Ayatollahi for their very helpful discussions. This work was supported by the National Science Foundation for Distinguished Young Scholars of China (Grant No. 11325211), the National Natural Science Foundation of China (Grant No. 11672147) and the Project 
of International Cooperation and Exchange NSFC (Grant No. 11511130057).

\section{References}

Ayatollahi, M., Pavier, M., Smith, D., 2002. Mode I cracks subjected to large T-stresses. International Journal of Fracture 117, 159-174.

Ayatollahi, M.R., Hashemi, R., 2007. Computation of stress intensity factors (KI, KII) and T-stress for cracks reinforced by composite patching. Composite Structures 78, 602-609.

Ayatollahi, M.R., Pavier, M.J., Smith, D.J., 1998. Determination of T-stress from finite element analysis for mode I and mixed mode I/II loading. International Journal of Fracture 91, 283-298.

Ayatollahi, M.R., Sedighiani, K., 2012. A T-stress controlled specimen for mixed mode fracture experiments on brittle materials. European Journal of Mechanics - A/Solids 36, 83-93.

Becker Jr, T., Cannon, R., Ritchie, R., 2001. Finite crack kinking and T-stresses in functionally graded materials. International Journal of Solids and Structures 38, 5545-5563.

Bettinson, A.D., O’Dowd, N.P., Nikbin, K., Webster, G.A., 2001. Two Parameter Characterisation of Crack Tip Fields under Creep Conditions, in: Murakami, S., Ohno, N. (Eds.), IUTAM Symposium on Creep in Structures. Springer Netherlands, pp. 95-104.

Broberg, K.B., 1999. Influence of T-stress, cohesive strength and yield strength on the competition between decohesion and plastic flow in a crack edge vicinity. International Journal of Fracture 100, 133-142.

Brown, S., 1966. Plane strain crack toughness testing of high strength metallic materials, Plane Strain Crack Toughness Testing of High Strength Metallic Materials. ASTM International.

Budden, P., Ainsworth, R., 1997. The effect of constraint on creep fracture assessments. International Journal of Fracture 87, 139-149.

Chao, Y., Zhu, X., Zhang, L., 2001. Higher-order asymptotic crack-tip fields in a power-law creeping material. International Journal of Solids and Structures 38, 3853-3875.

Chen, Y., 2000. Closed form solutions of T-stress in plane elasticity crack problems. International Journal of Solids and Structures 37, 1629-1637.

Dai, Y., Liu, D., Liu, Y., 2016. Mismatch constraint effect of creep crack with modified boundary layer model. Journal of Applied Mechanics 83, 031008-031016.

Dai, Y., Liu, Y., Chao, Y.J., 2017. Higher order asymptotic analysis of crack tip fields under mode II creeping conditions. International Journal of Solids and Structures 125, 89-107.

Du, Z.Z., Hancock, J.W., 1991. The effect of non-singular stresses on crack-tip constraint. Journal of the Mechanics and Physics of Solids 39, 555-567.

English, S.A., Arakere, N.K., 2011. Effects of the strain-hardening exponent on two-parameter characterizations of surface-cracks under large-scale yielding. International Journal of Plasticity 27, 920-939.

Fett, T., 1998. T-stresses in rectangular plates and circular disks. Engineering Fracture Mechanics 60, 631-652.

Fett, T., 2009. Stress Intensity Factors, T-stresses, Weight Functions: Supplement Volume. KIT Scientific Publishing.

Gao, H., Chiu, C.-H., 1992. Slightly curved or kinked cracks in anisotropic elastic solids. International Journal of Solids and Structures 29, 947-972. 
Henry, B., Luxmoore, A., 1994. Three-dimensional evaluation of the T-stress in centre cracked plates. International journal of fracture 70, 35-50.

Hoff, N., 1954. Approximate analysis of structures in the presence of moderately large creep deformations. Quarterly of Applied Mathematics 12, 49.

Hutchinson, J., 1968. Singular behaviour at the end of a tensile crack in a hardening material. Journal of the Mechanics and Physics of Solids 16, 13-31.

Larsson, S.G., Carlsson, A.J., 1973. Influence of non-singular stress terms and specimen geometry on small-scale yielding at crack tips in elastic-plastic materials. Journal of the Mechanics and Physics of Solids 21, 263-277.

Liu, S., Chao, Y.J., 2003. Variation of fracture toughness with constraint. International Journal of Fracture 124, 113-117.

Ma, H.S., Wang, G.Z., Xuan, F.Z., Tu, S.T., 2015. Unified characterization of in-plane and out-of-plane creep constraint based on crack-tip equivalent creep strain. Engineering Fracture Mechanics 142, 1 20.

Matvienko, Y.G., Shlyannikov, V., Boychenko, N., 2013. In - plane and out - of - plane constraint parameters along a three - dimensional crack - front stress field under creep loading. Fatigue $\&$ Fracture of Engineering Materials \& Structures 36, 14-24.

Meshii, T., Tanaka, T., Lu, K., 2010. T-Stress solutions for a semi-elliptical axial surface crack in a cylinder subjected to mode-I non-uniform stress distributions. Engineering Fracture Mechanics 77, 2467-2478.

Nakamura, T., Parks, D., 1990. Three-dimensional crack front fields in a thin ductile plate. Journal of the Mechanics and Physics of Solids 38, 787-812.

Nguyen, B., Onck, P., Van Der Giessen, E., 2000. On higher-order crack-tip fields in creeping solids. Journal of Applied Mechanics 67, 372-382.

Nikbin, K., 2004. Justification for meso-scale modelling in quantifying constraint during creep crack growth. Materials Science and Engineering: A 365, 107-113.

Norton, F.H., 1929. The creep of steel at high temperatures. McGraw-Hill Book Company, Incorporated.

O'Dowd, N.P., Shih, C.F., 1994. Two-parameter fracture mechanics: theory and applications. ASTM special technical publication 1207, 21-21.

Ren, X., Zhang, Z., Nyhus, B., 2009. Effect of residual stresses on the crack-tip constraint in a modified boundary layer model. International Journal of Solids and Structures 46, 2629-2641.

Rice, J., Rosengren, G., 1968. Plane strain deformation near a crack tip in a power-law hardening material. Journal of the Mechanics and Physics of Solids 16, 1-12.

Riedel, Rice, 1980. Tensile cracks in creeping solids. West Conshohocken, PA: ASTM STP 700, 112 130.

Roychowdhury, S., Dodds Jr, R.H., 2004. Effect of T-stress on fatigue crack closure in 3-D small-scale yielding. International Journal of Solids and Structures 41, 2581-2606.

Sherry, A., France, C., Goldthorpe, M., 1995. Compendium of T - stress solutions for two and three dimensional cracked geometries. Fatigue \& Fracture of Engineering Materials \& Structures 18, 141 155.

Shih, C.F., O'Dowd, N., Kirk, M., 1993. A framework for quantifying crack tip constraint, in: M., H.E., K.H., S., Dodds, R.H. (Eds.), Constraint effects in fracture. ASTM International, Philadelphia, pp. $2-20$.

Shlyannikov, V.N., Boychenko, N.V., Tartygasheva, A.M., 2011. In-plane and out-of-plane crack-tip 
constraint effects under biaxial nonlinear deformation. Engineering Fracture Mechanics 78, 1771 1783.

Tada, H., Paris, P., Irwin, G., 2000. The analysis of cracks handbook. New York: ASME Press.

Tan, J.P., Wang, G.Z., Tu, S.T., Xuan, F.Z., 2014. Load-independent creep constraint parameter and its application. Engineering Fracture Mechanics 116, 41-57.

Tvergaard, V., 2008. Effect of T-stress on crack growth under mixed mode I-III loading. International Journal of Solids and Structures 45, 5181-5188.

Tvergaard, V., Hutchinson, J.W., 1994. Effect of T-stress on mode I crack growth resistance in a ductile solid. International Journal of Solids and Structures 31, 823-833.

Wang, G.Z., Liu, X.L., Xuan, F.Z., Tu, S.T., 2010. Effect of constraint induced by crack depth on creep crack-tip stress field in CT specimens. International Journal of Solids and Structures 47, 51-57.

Williams, 1957. On the stress distribution at the base of a stationary crack. Journal of Applied Mechanics 24, I09.

Yang, B., Ravi-Chandar, K., 1999. Evaluation of elastic T-stress by the stress difference method. Engineering Fracture Mechanics 64, 589-605.

Yatomi, M., O’Dowd, N.P., Nikbin, K.M., Webster, G.A., 2006. Theoretical and numerical modelling of creep crack growth in a carbon-manganese steel. Engineering Fracture Mechanics 73, 1158-1175.

Ye, T., Suo, Z., Evans, A., 1992. Thin film cracking and the roles of substrate and interface. International Journal of Solids and Structures 29, 2639-2648.

Yuan, H., Brocks, W., 1998. Quantification of constraint effects in elastic-plastic crack front fields. Journal of the Mechanics and Physics of Solids 46, 219-241.

Zhao, L., Xu, L., Han, Y., Jing, H., 2015a. Quantifying the constraint effect induced by specimen geometry on creep crack growth behavior in P92 steel. International Journal of Mechanical Sciences 94-95, 63-74.

Zhao, L., Xu, L., Han, Y., Jing, H., 2015b. Two-parameter characterization of constraint effect induced by specimen size on creep crack growth. Engineering Fracture Mechanics 143, 121-137. 